Technical Report 1090

\title{
Problem Solving of Mid-Career Army Officers: Identifying Natural Reasoning
}

Julia Pounds

Human Resources Research Organization

Jon J. Fallesen

U.S. Army Research Institute

November 1998

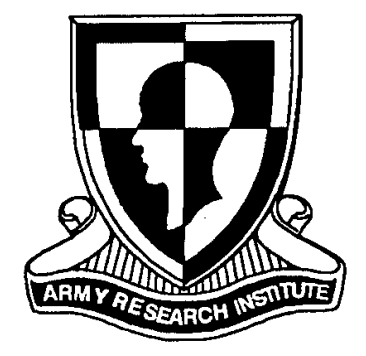

United States Army Research Institute for the Behavioral and Social Sciences

Approved for public release; distribution is unlimited. 


\section{U.S. Army Research Institute \\ for the Behavioral and Social Sciences}

A Directorate of the U.S. Total Army Personnel Command

EDGAR M. JOHNSON Director

Research accomplished under contract

for the Department of the Army

Human Resources Research Organization

Technical Review by

Lee Scott Ehrhart, MITRE Corporation

Rebecca Pliske, Klein Associates Inc.

\section{NOTICES}

DISTRIBUTION: Primary distribution of this Technical Report has been made by ARI. Please address correspondence concerning distribution of reports to: U.S. Army Research Institute for the Behavioral and Social Sciences, Attn: TAPC-ARI-PO, 5001 Eisenhower Ave., Alexandria, VA 22333-5600.

FINAL DISPOSITION: This Technical Report may be destroyed when it is no longer needed. Please do not return it to the U.S. Army Research for the Behavioral and Social Sciences.

NOTE: The findings in this Technical Report are not to be construed as an official Department of the Army position, unless so designated by other authorized documents. 


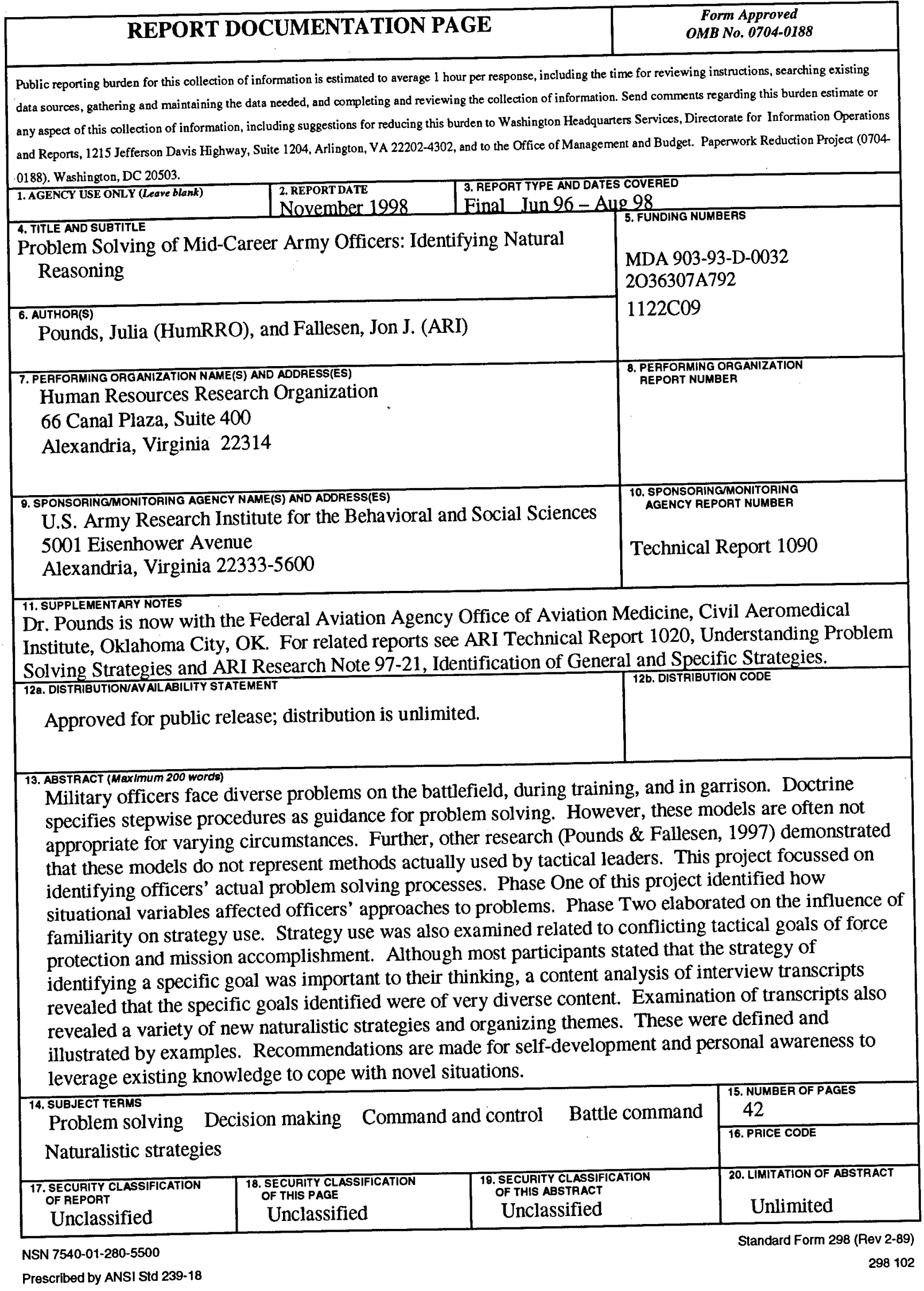




\title{
Problem Solving of Mid-Career Army Officers: Identifying Natural Reasoning
}

\author{
Julia Pounds \\ Human Resources Research Organization \\ Jon J. Fallesen \\ U.S. Army Research Institute
}

Fort Leavenworth Research Unit

Stanley M. Halpin, Chief

U.S. Army Research Institute for the Behavioral and Social Sciences 5001 Eisenhower Avenue, Alexandria, Virginia 22333-5600

November 1998

Army Project Number

Manpower and Personnel

20363007 A792

Approved for public release; distribution is unlimited. 
The Fort Leavenworth Research Unit of the U.S. Army Research Institute for the Behavioral and Social Sciences (ARI) conducts research to enhance battle command and staff capabilities of the Army. There is growing interest in how officers actually make decisions and solve military problems. This is in stark contrast to years of research that focused on why people do not follow a rational, ideal model for decision making. This latter perspective viewed decision makers as flawed or biased when they did not act like perfect processors of information, even when important information was not available or was in conflict with other information. Decision making training was based on ideal models of decision making that considered people to be analytical and rational in their judgments.

Although the rational perspective continues to influence the doctrine and training related to decision making, more recently, researchers have dropped "ideal" models and have tried to understand how it is that people actually make decisions in complex, dynamic situations. Within ARI we have adopted a broader view of the important, operative tasks. The task of interest is no longer simply the decision process, but to understand how officers bring their experience to bear in complex and novel situations. To understand competent tactical problem solving we must also understand how problems are identified and represented, how one's knowledge influences which solutions are explored, and how plans are determined, enacted, and controlled.

This report focused on identifying the natural problem solving strategies which individuals bring to the task. The project elaborated on the influence of task familiarity on one's approach to a problem and identified new problem solving strategies, as well as other overarching themes that can act to direct problem solving. The report provides a basis for officer development.

Briefings on these findings were given to LTG Vollrath, DCSPER, in November 1997, and to COL Tystad, Director of the Center for Tactics, in June 1998. A related paper was given at the Fourth Conference on Naturalistic Decision Making, May 1998.

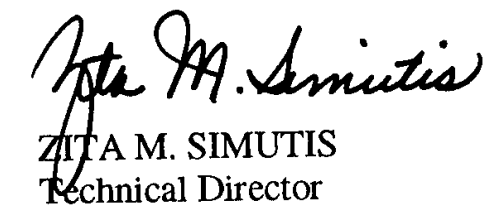




\section{PROBLEM SOLVING OF MID-CAREER ARMY OFFICERS: IDENTIFYING NATURAL REASONING}

\section{EXECUTIVE SUMMARY}

\section{Research Requirement:}

In current and future battlefield situations, military leaders must be ready to solve novel problems in a variety of unexpected situations. To assist tactical leaders in decision making in complex and dynamic situations, the Army needs to have a better understanding of how people prefer to solve problems and how to leverage these strengths. To date, military services have largely relied on economic decision theories that call for avoiding biases through objective, exhaustive, and systematic comparison of options. Recent findings, however, show the shortcomings of rigid procedures and point to naturalistic strategies as a preferred standard. Tactical decision makers face many sources of contextual variation, novelty, and complexity. Simplistic "6 step models" or exhaustive comparisons of options are not sufficient for the complexities of actual situations. This report provides details about natural problem solving approaches and individual strategies, some of which were identified in earlier studies. It also identifies themes and values of military leaders that are brought to a situation and which can influence problem solving. By identifying and understanding new strategies, approaches, and themes, a base of knowledge can be developed to facilitate improved problem solving in complex dynamic situations.

\section{Procedure:}

Eighty-two military leaders discussed their solutions to three tactical situations. Individual differences in familiarity with the problem were examined relative to the preferred approach adopted by the problem solver. Solutions to both tactical problems were categorized based on how the recommendation dealt with higher-order concepts of force protection and mission accomplishment relative to the original mission and to familiarity. Strategies associated with these two higher order concepts were identified. Transcripts of the interviews were also examined for new naturalistic strategies that were not yet identified by the problem solving literature. The strategy rated as highly important by most participants--"Identified a specific goal."--was examined for its associated explanations. Remarks from fifty-eight transcripts were categorized; they illustrated the diversity of thinking that can exist about one strategy.

Findings:

Examination of naturalistic strategies, themes, and values led to three general observations:

1. About a third of the participants appeared to hold general, over-riding themes which reappeared throughout their discussion of a problem. Thirteen themes were identified with descriptions and examples. If themes are higher conceptual structures, they may be more useful as the situation becomes more familiar. Studies of expertise have concluded that experience is associated with the greater use of abstract concepts.

2. Twenty-two new naturalistic strategies were identified. These reasoning strategies could be used to clarify and elaborate the processes of recognition, dominance, mental simulation, etc. by detailing how specific strategies are used as part of these more general approaches. Naturalistic models have primarily 
focused on examining how decision makers develop one option using recognition processes. Although this is characteristic when the problem solver is familiar with the domain, the data from an interim report (Pounds \& Fallesen, 1997) showed that in unfamiliar problems, a dominance process of attribute comparison was frequently used. While some people do just develop one option, natural strategies for multiple option comparisons based on attribute evaluations have not been clarified. One likely candidate for future examination of multiple option comparisons in naturalistic situations is comparison testing.

3. Results demonstrated that mere advocacy for the use of any particular strategy does not necessarily guarantee that all users focus on the same content of the strategy. The content can vary across individuals depending upon their familiarity with the problem or the themes and values that they find relevant in the situation. Thus, doctrinal guidance to employ a particular strategy does not necessarily guarantee similar outcomes.

\section{Utilization of Findings:}

Most studies of problem solving strategies have been conducted in impoverished environments, using restricted laboratory tasks, often not accounting for the role of the problem solver's prior knowledge and experience. Thus, previous findings have emphasized strategies that lead to optimal problem solving in simple environments. However, these optimizing strategies are often brittle in that small changes in conditions can lead to large decreases in a strategy's usefulness. Strategies which problem solvers use in complex environments need to be examined. The findings from this project identified particular ways to accomplish this goal.

Findings are intended to be used by researchers, curriculum specialists, and decision aid developers. All three communities must have an understanding of how tactical decision makers naturally think about complex situations so that natural strengths can be leveraged through instruction and practice. Until now, many of the influences and strategies in these on-the-job problems were not identified. 
PROBLEM SOLVING OF MID-CAREER ARMY OFFICERS: IDENTIFYING NATURAL

REASONING

\section{CONTENTS}

Page

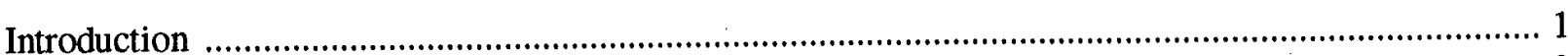

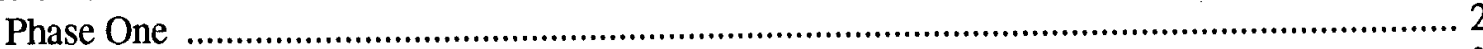

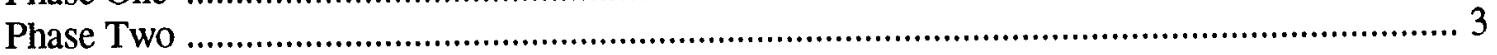

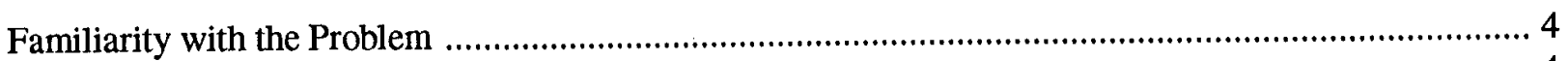

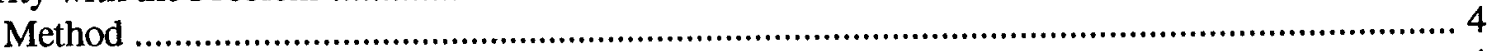

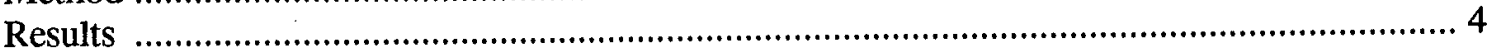

Strategies Associated with Higher-Order Problem Solving Concepts ............................................... 6

Method

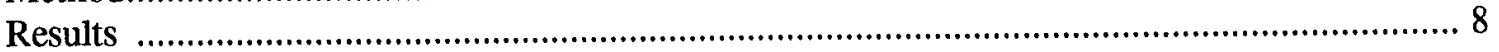

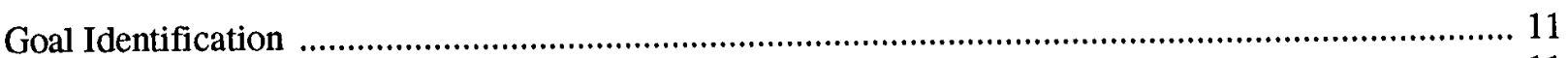

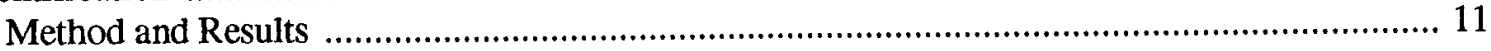

Organizing Themes: Beliefs, Attitudes, and Values ..................................................................... 13

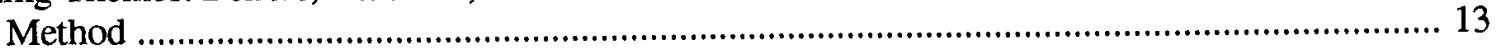

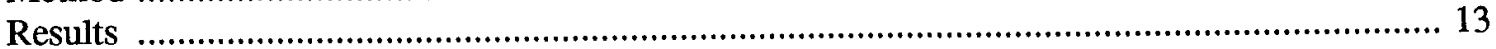

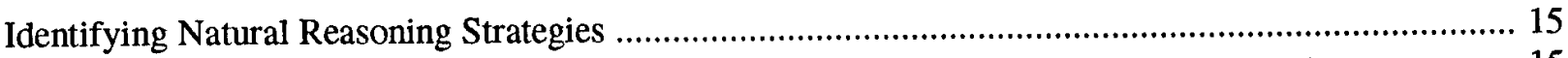

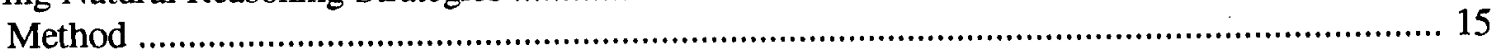

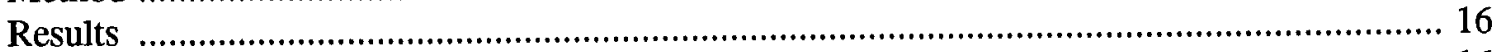

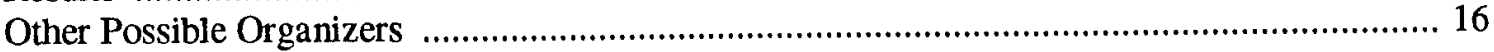

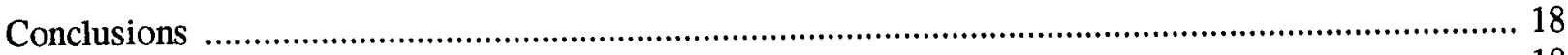

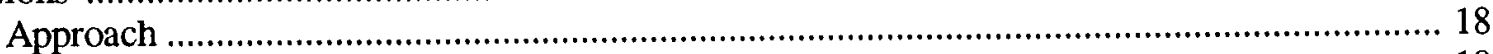

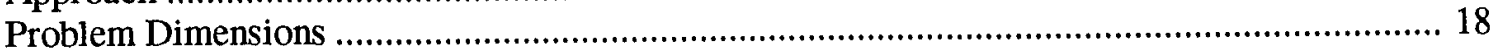

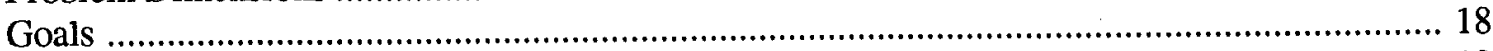

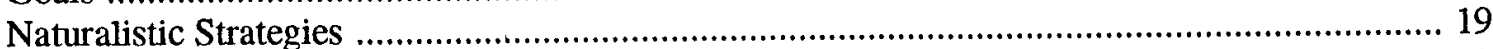

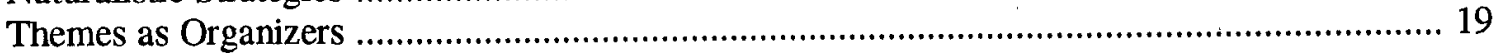

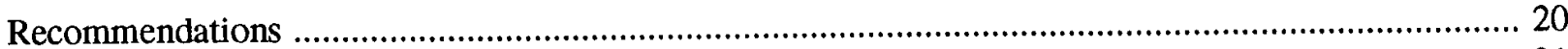

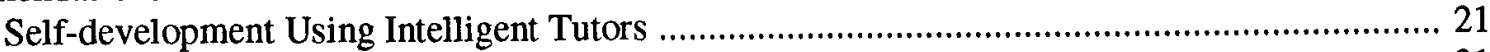

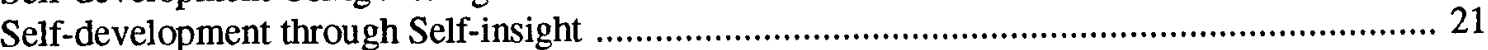

Using Existing Knowledge Efficiently and Effectively ...................................................... 22

References

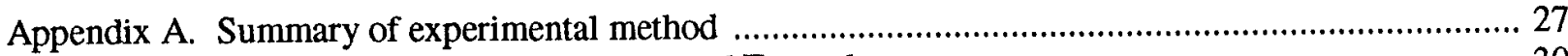

B. Natural Strategies, Definitions, and Examples ........................................................... 30 


\section{LIST OF TABLES}

Table 1. Frequency of Participants Using Same or Different Approach between Tactical Problems..... 4

2. Types of Solution for Force Protection by Problem ……..................................................... 7

3. Types of Solution for Mission Accomplishment by Problem ..................................................... 7

4. Indicators of Force Protection Categories over Both Scenarios ............................................... 8

5. Indicators of Mission Accomplishment Categories ................................................................. 9

6. Association Between Demographic Variables and Solution Emphasis .................................. 10

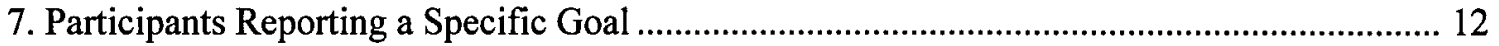

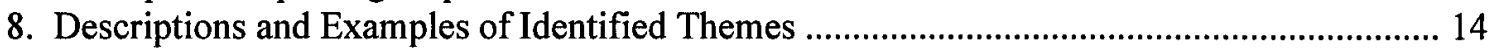

9. Natural Strategies, Descriptions, and Frequency …............................................................ 17

\section{LIST OF FIGURES}

Figure 1. Questions addressed in Phas 2 of the research ............................................................... 3

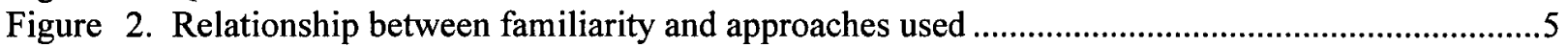

Figure 3. Relationship among recommendation and familiarity .................................................. 10 


\title{
PROBLEM SOLVING OF MID-CAREER ARMY OFFICERS: IDENTIFYING NATURAL REASONING
}

\author{
Introduction
}

Military leaders face a diversity of challenges on the battlefield, during training, and in garrison. When asked to recall particularly memorable problems from their experiences, military leaders listed a range of problems with equipment, personnel, and weather among others. The following excerpts illustrate this variety.

- As we moved out in a night convoy during Desert Storm, our fire direction vehicle's trailer carrying our equipment flipped over. The convoy kept going, but without the fire direction equipment the platoon would not be able to fire its missions. What should we do so that we could continue to execute the mission-leave the trailer or drop back from the convoy?

- During an NTC [National Training Center] exercise, I as the company executive officer was put in command of a motorized rifle battalion. Our mission was to portray the OPFOR [opposing forces] during a battalion ARTEP [Army Technical Evaluation Program] preparation. I had no experience in this role. What should I do?

- During an NTC exercise, my mission was to conduct armed reconnaissance missions--not something we had been geared for. As the aviation unit, we still had to control the ground force, coordinate the close battlefield, and conduct a "violent, fast, lethal attack" while sustaining aircraft on station with command and control for 32 hours. How could all this be accomplished?

- I was chief commander of 3 teams of response aircraft. When Blackhawks were fired upon, I was short one aircraft of the required 6 . How could I schedule a response to the enemy threat with the resources available?

- An infantry officer had to step into the position of forward support battalion $S 3$ two weeks before the battalion's external evaluation. How could he learn about the job and get done what needed to be done?

- I was a new S3 for a new battalion commander in our first FTX [field training exercise]. The battalion did a night jump across a mountain ridge. As the convoy moved out, a blizzard began. Troops facing low visibility and darkness had to navigate through the snowy mountain terrain using blackout-driving procedures. What procedures could be used to get everyone down safely?

- The enemy was not laid down as expected. The plan was for friendly forces to conduct an offensive but the enemy was arranged in a non-doctrinal array and their plan looked like they were also conducting an offensive. Their artillery was too far forward to be a defensive array. Should our friendly forces continue with the offensive or go on the defensive?

- In a desert training exercise the observer-controllers were not all connected by a secured radio net and not all vehicles had the equipment to enable one. It had to be arranged quickly and without impairing the exercise. How could we configure all vehicles to be usable with the available equipment and manpower? 
- I was assigned as battalion S4 in Korea. I had no preparation for administration, regulations, etc. I also had to do tactical planning and logistics. How should I arrange tasks to accomplish all my goals?

- As battery commander, my unit was short personnel. I did not want to use officers to replace missing personnel but some people were kept from going to the field for training because of lack of personnel to fill howitzer teams. How could everyone receive the necessary training while maintaining safety and despite personnel shortages?

- During a tank platoon ARTEP-- a road march to an AA [assembly area] at night-- my platoon got disoriented and lost. Some troops wanted to sleep before taking care of other priorities (security, communications, etc.). One of my tank commanders went to sleep instead of tending to these things. What actions should I take to handle this situation?

- I was a platoon leader, and I had a mission to find and watch an enemy intelligence cell. It was located but communication with the company commander went down. Meanwhile, I could hear other forces being fired upon. Should I continue with my original mission or go to assist other friendly forces who were under enemy fire?

As guidance for problem solving, doctrine specifies variations of a stepwise procedure (Headquarters, 1997, FM 101-5). However, the above examples demonstrate that time and circumstances often do not permit the use of these models. Moreover, research has shown that military leaders in tactical situations tend not to rely on the doctrinally recommended decision making procedures (see Fallesen, 1993). To more accurately identify officers' actual decision making processes, a general research plan was initiated. The first goal of the project was to describe how military leaders actually go about solving problems. The notion was, that once determined, this information could then be used to identify ways to improve naturally occurring thinking skills rather than trying to impose a prescriptive but generally unusable method.

Phase One

Phase one of this project examined how military leaders employed previously identified strategies to find solutions. Strategic problem solving was examined from four perspectives: general approach, strategies, problem types, and individual differences. Several assumptions were made based on a review of the literature (Pounds \& Fallesen, 1994). One, it was assumed that when faced with a problem, people use general, higher-order methods of thinking when approaching a problem to organize more specific strategies. Adoption of an approach might depend on characteristics of the problem, situation, or person. These general organizers were labeled "approaches." Two, it was assumed that strategies are mid-level thinking processes which organize and transform information while it is being used.

This research surveyed the importance of previously identified approaches and strategies of the thinking of 82 mid-career U.S. Army officers. Participants reported differential use of the approaches and strategies previously identified in other literatures (Pounds \& Fallesen, 1994). The first analysis focused primarily on the more familiar maneuver problem and the general and specific approaches participants employed to make a recommendation about it. The method for collecting and summarizing the data were summarized in an interim report (Pounds \& Fallesen, 1997) and details are given in Appendix A.

Results demonstrated how the processes of problem solving are influenced by one's approach to problems, the type of problem and familiarity with the problem. Problems were associated with different approaches, depending upon whether the problem was more or less familiar. Moreover, different patterns 
of strategies were associated with different solutions within the familiar problem. Taken together, these results suggested that problems are approached and strategies are employed differently depending on characteristics of both the problem and of the problem solver.

At the end of phase one several lines of investigation remained. The recommended solutions for the unfamiliar problem had not been examined. Also, the question of whether different patterns of strategies would be associated with higher-order dimensions of the solutions (e.g., mission accomplishment) had not been examined. Individual differences and preferences for approaching problems needed further elaboration. Most importantly, the transcripts of the interviews needed to be examined for evidence of yet unidentified strategies used in naturalistic thinking processes.

\section{Phase Two}

This paper reports the results of phase two. Phase two of this project addressed multiple questions to examine characteristics of the problem and of the problem solver, and to identify strategies that emerged naturally during problem solving (see Figure 1). Because traditional decision making research has given little attention to real-world problem solving situations, the interview transcripts were examined for different strategies that may have been either unnoted by traditional research or emergent only in naturalistic tasks. Qualitative methods and descriptive analyses were frequently employed to explore participants' narratives.

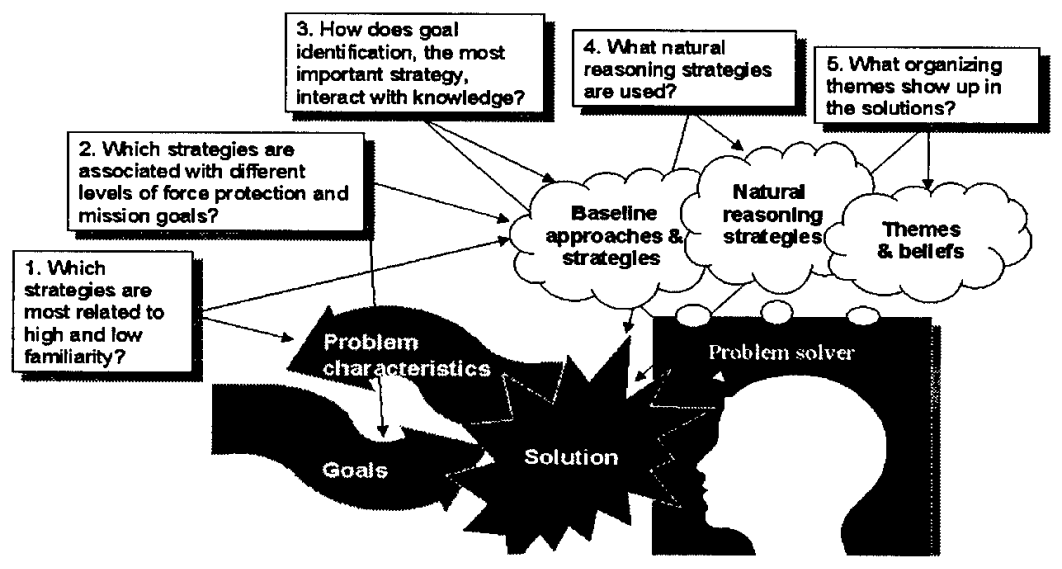

Figure 1. Questions addressed in Phase 2 of the research.

First, the relationship between familiarity with the problems and approach to the problem from phase one was elaborated. Second, the recommended courses of action for both problems were categorized on higher-order tactical dimensions of goals, and then the strategies associated with these goals were examined. Third, one strategy was used to show how strategy use interacts with content knowledge. Fourth, the original interview transcripts were reviewed for evidence of naturalistic problem solving strategies. Finally, the working concept of "approach" was reevaluated and elaborated. Other possible "organizers" that might facilitate or hinder problem solving were identified. 
Familiarity with the Problem

In general, research has demonstrated that people who are more experienced with a situation tend to approach it differently than people who are less familiar with that problem (Klein, 1988). Moreover, more experienced people often focus on more abstract characteristics of the problem and solve problems differently (Fallesen, 1993; Shanteau, 1992).

Interim report analyses confirmed that not all participants were familiar with the two tactical problems used. Familiarity with the problem was not significantly related to using either of the two process-based approaches, however, problem differences were related to whether participants used a recognition or dominance approach to the problem. Interim report findings of positive and negative relationships between the four approaches suggested that participants preferred to use either attributes of the problem or a prescriptive process but not both. For the purposes of this report, the goal was to elaborate the relationship between approaches based on attributes of the problem or informal means (recognition and dominance) and the rule-based approaches or formal means (analytic and procedural).

Method

Ratings for perceived familiarity with the problem were collapsed across the two tactical problems. The distribution of familiarity ratings was then trisected. Low, medium, and high familiarity groups represented 37,33 , and 30 percent of the available sample, respectively ( $n=63$ data points). This method ignored the effects of problem type and focused on the interaction between familiarity and preferred approach.

Results

Transcripts from 14 participants who gave both familiarity ratings and specific approach ratings for the two tactical problems were examined. Participants could have elected to use the same or different type of approach for each problem, however, eleven people stayed within the same type across both problems (seven used attribute-based and four used process-based). Only three people switched between types. Table 1 shows the change in approaches between tactical problems.

Table 1

Frequency of Participants Using Same or Different Approach for Two Different Tactical Problems

\begin{tabular}{|c|c|c|c|c|c|}
\hline & & & miliarity & & \\
\hline & LevelWhe & oblems w & & Mixed & miliarity \\
\hline Type of Approach & Low & Medium & High & $\begin{array}{c}\text { Rescue } \\
\text { Problem } \\
\text { More Familiar }\end{array}$ & $\begin{array}{c}\text { Maneuver } \\
\text { Problem More } \\
\text { Familiar }\end{array}$ \\
\hline Informal, Attribute & 0 & 0 & 1 & 1 & 5 \\
\hline Formal, Process & 2 & 1 & 0 & 0 & 1 \\
\hline Switched & 0 & 1 & 0 & 1 & 1 \\
\hline
\end{tabular}

Switching of approach might have depended on participants' familiarity with the problem. However, when ratings of familiarity groups were examined relative to approach, nine people (64 percent) were in different familiarity groups between problems but stayed within the same type of approach. That is, familiarity ratings from nine people switched between low, medium, or high familiarity groups across problems but they had rated themselves as using either an attribute-based or a process-based approach across both problems. Only ratings from four people had consistent familiarity 
groupings and approach over both problems. This small sample of responses provides some evidence that individual consistency of approach exists.

Participants' point assignments for the four specific approaches were examined relative to only low and high levels of familiarity. A general linear model analysis showed no relationship between Analytic or Procedural approaches and level of familiarity (low, high). On the other hand, both Recognition and Dominance approaches were significantly related to level of familiarity. As familiarity increased, reported use of a recognition approach increased, $F(1,40)=18.95, M S \mathrm{e}=771.89, p<.0001$. On the other hand, as level of familiarity increased, reported use of Dominance approach decreased $F(1$, $40)=9.81, M S \mathrm{e}=749.73, p<.0032$. Figure 2 shows this relationship between the low familiarity and high familiarity groups.

This is further evidence that use of both Recognition and Dominance are approaches which consider primarily the attributes of the problem, whereas use of process-based Analytic and Procedural approaches imply that application of the rules will guarantee a satisfactory outcome. Problem solvers using a Recognition approach rely primarily on identifying as familiar the arrangement of information in the current situation. On the other hand, problem solvers using a Dominance approach rely primarily on manipulating dimensions of the problem to find a course of action which is better

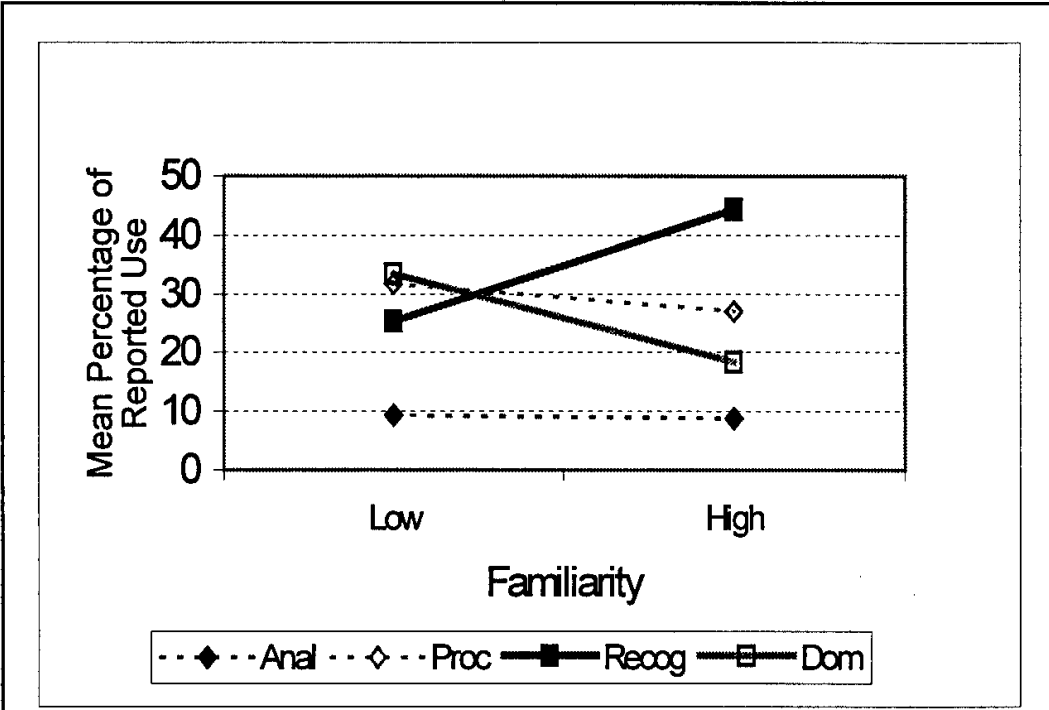

Figure 2. Relationship between familiarity and approaches used. on all (or most) dimensions than the others. Neither of these would be possible without some knowledge about the attributes of the situation, even if the situation itself is a novel one.

To begin to tease apart these relationships, the low and high familiarity groups were examined to determine which strategies were the best indicators for each group. A sequence of discriminant analyses were performed for these two groups by first entering all 48 strategies into a step-wise analysis $(p=.25$ to enter). The resulting set of 11 strategies was then entered as indicators in a discriminant analysis.

This revealed that use of the strategy, Thought of differences between the information in this problem and what was already known from past experience, was a positive indicator-that is, more likely to be used by those participants having high familiarity with the problem. This strategy was a negative indicator for-or more likely to be used by-participants having low familiarity with the problem. Although the following group of strategies were positive indicators used by both familiarity groups, they were more likely to be associated with the presence of high familiarity.

- Thought of similarities between the information in this problem and what was already known from past experience.

- Determined parts of the plan that would be prone to flaws.

- Spent time considering various perspectives on the situation. 
- Kept the set of things to think about as small as possible.

- Chose the option that has at least one important characteristic.

- Some options were eliminated before comparing options.

The strategy Wrote down everything that I knew about the problem was a positive indicator for the presence of low familiarity and a negative indicator for the presence of high familiarity. However, low familiarity was also more likely to be indicated by use of the following strategies.

- Deconflict information.

- Imagined the worst outcomes.

- The best option should have met certain desired criteria.

These results are evidence that one's level of familiarity with a problem is related to the specific strategies employed to solve it. Further, this provides more specific information that can be used to refine concepts of "approach" by identifying specific strategies associated with differing levels of familiarity. Examination of how one's preferred approach is coordinated with prior knowledge and strategy use would be useful to elaborate on current models of recognition and dominance. For example, what strategies were associated with preference for a dominance approach rather than a procedural approach? The current data set was not sufficient to examine the strategy indicators for each approach within levels of familiarity with this method.

A finer grained understanding of the strategic procedures underlying these models would also highlight points where training could be provided to improve efficiency of naturally occurring strategies. For instance, those people relying on dominance may think about the situation and its attributes differently than those people using a procedural approach. Whether this is the case and whether differences in treatments results in differences in outcomes is not known. This understanding would be particularly useful for the low familiarity situations since routine, familiar problems arguably do not pose the same level of personal, tactical, organizational, and national threat as do novel cases of the same magnitude.

\section{Strategies Associated with Higher-order Problem Concepts}

Although doctrinal guidance specifies process-based problem solving procedures for dynamic, complex tactical situations, rigid doctrinal procedures often do not fit with available time for planning Thus, they are rarely useful in actual practice as they were intended, that is, to guide primary thinking and to influence outcomes (Fallesen, 1993). Thus, one goal of this research was to begin to specify what was actually occurring in practice. Although research has demonstrated that a recognition process is used when the person has high levels of expertise, it has not been determined what strategies are used in other situations. This is unfortunate since people are also called on to make decisions in situations where they have little expertise.

To begin to answer this question, it was important to note whether different strategies were associated with different aspects of the problem. This would be considered a demonstration that strategy use could be associated with, or a response to, the various parts of the problem and also that variable strategy use could be associated with different conclusions in situations where searching for a "right" answer is not appropriate.

Complex and dynamic situations are often characterized by multiple and opposing goals. Two high-level but often conflicting goals of tactical operations are the protection of one's force and the 
accomplishment of one's mission. Strategy ratings were examined to determine how strategy use was related to problem goals.

Method

Solutions to both tactical problems were categorized based on how the recommendation dealt with higher-order concepts of Force protection and Mission accomplishment relative to the original mission. Table 2 shows how solutions were identified as best fitting one of four categories of Force protection ranging from 1 (likely to provide minimum protection in the current situation) to 4 (likely to provide maximum protection in the current situation).

Table 2

Types of Solution for Force Protection by Problem

\begin{tabular}{|c|c|c|c|c|}
\hline Problem & 1 & 2 & 3 & 4 \\
\hline Maneuver & $\begin{array}{c}\text { Fix or bypass enemy } \\
\text { in AA and retake } \\
\text { bridge rapidly. }\end{array}$ & $\begin{array}{c}\text { Attack \& clear } \\
\text { through AA to the far } \\
\text { side of bridge. }\end{array}$ & $\begin{array}{c}\text { Attack and occupy } \\
\text { AA. }\end{array}$ & $\begin{array}{c}\text { Hold up and assume } \\
\text { defensive posture. }\end{array}$ \\
\hline Rescue & $\begin{array}{c}\text { Ignore enemy } \\
\text { reaction force. } \\
\text { reaclude enemy } \\
\text { rextract before arrival. }\end{array}$ & $\begin{array}{c}\text { Be reactive to } \\
\text { counter enemy } \\
\text { reaction force. }\end{array}$ & $\begin{array}{c}\text { Be proactive to } \\
\text { counter enemy } \\
\text { reaction force. }\end{array}$ \\
\hline
\end{tabular}

Solutions that focussed on gaining the bridge in the maneuver scenario also appeared to implicitly assume battlefield dominance. Similarly, solutions to the rescue problem that ignored the enemy reaction force or proposed to extract the hostages before the enemy reaction force could arrive appeared to assume a situational dominance which could have been unwarranted.

Table 3 shows how the same solutions were also categorized as best fitting one of four categories of Mission accomplishment ranked from 1 (least likely/focused to accomplish the mission goal) to 4 (most likely to accomplish the mission goal). Recommendations for the rescue problem are ranked in the same direction for both force protection and Mission accomplishment. The rankings for the maneuver problem recommendations were reversed between goals. That is, a recommended course of action having minimum force protection in the maneuver scenario was ranked as being most likely to have maximum mission accomplishment.

Table 3

Types of Solution for Mission Accomplishment by Problem

\begin{tabular}{|c|c|c|c|c|}
\hline \multicolumn{2}{|c|}{ Levels of Mission Accomplishment } \\
\hline Problem & 1 & 2 & 3 & 4 \\
\hline Maneuver & $\begin{array}{c}\text { Hold up and } \\
\text { assume defensive } \\
\text { posture. }\end{array}$ & $\begin{array}{c}\text { Attack and occupy } \\
\text { AA. }\end{array}$ & $\begin{array}{c}\text { Attack \& clear } \\
\text { through AA to far } \\
\text { side of bridge. }\end{array}$ & $\begin{array}{c}\text { Fix or bypass enemy } \\
\text { in AA and retake } \\
\text { bridge rapidly. }\end{array}$ \\
\hline Rescue & $\begin{array}{c}\text { Ignore enemy } \\
\text { reaction force. }\end{array}$ & $\begin{array}{c}\text { Preclude enemy } \\
\text { reaction force and } \\
\text { extract before arrival. }\end{array}$ & $\begin{array}{c}\text { Be reactive to } \\
\text { counter enemy } \\
\text { reaction force. }\end{array}$ & $\begin{array}{c}\text { Be proactive to } \\
\text { counter enemy } \\
\text { reaction force. }\end{array}$ \\
\hline
\end{tabular}


When categorized according to mission accomplishment, solutions in groups 2 and 3 were primarily oriented on carrying out the last order. On the other hand, maneuver solutions in group 1 focussed on the uncertainty introduced into the mission by the new information about enemy in the assembly area. On the other hand, category 1 solutions to the rescue problem did not consider the element of uncertainty associated with the possible arrival of a reinforcing enemy force. level 4 solutions to both the maneuver and rescue problems remained focussed on important aspects of the mission.

In real-life problem situations, such as those related by the participants of this study, these goals of Force protection and Mission accomplishment often conflict. For example, the commander in charge of dispatching aircraft to protect the Blackhawks (see page 1) had to consider both his responsibility to provide adequate resources while at the same time protecting the Blackhawk and other aircraft crews. Similarly, the battery commander (see page 2 ) had to accomplish his training goals while maintaining safety standards.

\section{Results}

The same methodology of using a set of discriminant analysis procedures in phase one was employed as exploratory analyses for both force protection and mission accomplishment (Kelecka, 1980; SAS institute, 1988; Tabachnick \& Fidell, 1989). Separate sets of analyses were conducted for each goal. First, the entire set of 48 strategies was entered into the step-wise discriminant analysis ( $p=.25$ to enter) using strategy importance ratings as predictor variables for the four category levels. The subset of strategies identified by this analysis as best indicators associated with the levels of the goal were then entered into a second discriminant analysis to identify whether each strategy was positively or negatively associated with each level of the higher-order concept.

Force protection. Analysis of the goal of force protection showed that of the sixteen strategies that emerged from the first analysis as significant indicators of the four Force protection categories, eight strategies discriminated between levels (Table 4). For example, using the strategy Considered details before the big picture was associated with recommended courses of action that would emphasize protection and preservation of force and manpower (a positive indicator of force protection level 4). In

Table 4

Indicators of Force Protection Categories over Both Scenarios

\begin{tabular}{|c|c|c|c|c|}
\hline \multirow[b]{2}{*}{ Strategies } & \multicolumn{4}{|c|}{ Levels of Force Protection } \\
\hline & 1 & 2 & 3 & 4 \\
\hline P13. Considered details before the big picture. & - & - & - & \\
\hline C8. Options were judged qualitatively. & & & & \\
\hline $\begin{array}{l}\text { C3. An option was selected if it met standards specified by } \\
\text { others. }\end{array}$ & & & - & \\
\hline $\begin{array}{l}\text { P2. Thought of differences between the information in this } \\
\text { problem and what was already known from past experience. }\end{array}$ & & - & & \\
\hline $\begin{array}{l}\text { C17. Some options were eliminated before comparing } \\
\text { options. }\end{array}$ & & & & - \\
\hline P15. Imagined the best outcomes. & & & & - \\
\hline $\begin{array}{l}\text { C19. Acceptable options were reexamined to see if one had } \\
\text { more important characteristics than another did. }\end{array}$ & & & & - \\
\hline $\begin{array}{l}\text { C6. An option's disadvantage was considered important only } \\
\text { when it was a large disadvantage. }\end{array}$ & & - & - & - \\
\hline
\end{tabular}


the maneuver problem to take the bridge, this strategy was associated with holding back and waiting. In the hostage rescue problem, this was associated with taking proactive actions to neutralize the threat from the enemy reaction force.

On the other hand, reported use of the strategy An option's disadvantage was considered important only when it was a large disadvantage was associated with recommended courses of action that put less emphasis on protection and preservation of force, that is, a positive indicator of force protection level 1. In the maneuver problem this would be the recommendation to fix or bypass the enemy in the assembly area and either establish an alternate assembly area or drive directly for the bridge. In these recommendations the potential enemy force left to one's rear, potential size of an enemy force north of the river, and potential disruption of the division timeline posed the major threats to forces. In the hostage rescue problem the recommended courses of action tended to be associated with no mention of a potential threat from the enemy reaction force.

Mission accomplishment. Analysis of the goal of mission accomplishment showed that of the fourteen strategies that emerged from the first analysis as significant indicators of the four Mission accomplishment categories; nine strategies discriminated among the levels of recommendations (Table 5).

For example, these results suggest that the reported use of the strategy, Imagined the worst outcomes, was associated with recommended courses of action that focused on getting to the river (in the bridge maneuver problem) and considered how to deal with the threat posed by the enemy reaction force (in the hostage rescue problem).

On the other hand, reported use of the strategy, Used general and approximate comparisons, also tended to be associated with recommended courses of action in the bridge problem that would stop forward movement. Participants who reported using this strategy to think about the hostage problem also tended to make recommendations that did not include consideration for the threat posed by the enemy reaction forces.

Table 5

Indicators of Mission Accomplishment Categories

\begin{tabular}{|l|c|c|c|c|}
\hline \multirow{2}{*}{ Strategies } & \multicolumn{3}{|c|}{ Levels of Mission Accomplishment } \\
\cline { 2 - 5 } & 1 & 2 & 3 & 4 \\
\hline P16. Imagined the worst outcomes. & - & - & + & + \\
\hline $\begin{array}{l}\text { C4. Chose the option that had at least one } \\
\text { important characteristic. }\end{array}$ & - & + & + & + \\
\hline P28. Considered the relevancy of information. & - & + & + & + \\
\hline $\begin{array}{l}\text { C5. Chose the option that had at least one important } \\
\text { characteristic. }\end{array}$ & + & - & + & + \\
\hline $\begin{array}{l}\text { C6. An option's disadvantage was considered } \\
\text { important only when it was a large disadvantage. }\end{array}$ & + & - & - & + \\
\hline $\begin{array}{l}\text { P7. Looked at the problem in terms of a story to } \\
\text { develop a fuller understanding. }\end{array}$ & - & + & - & - \\
\hline P23. Used specific and precise comparisons. & + & + & - & - \\
\hline P26. Considered the reliability of information. & + & + & + & - \\
\hline P24. Used general and approximate comparisons. & + & - & - & - \\
\hline
\end{tabular}


One relevant concern is the role of training and experience in determining recommendations. Some research literature exists which links the use of particular strategies to levels of experience. For example, experts tend to break complex problems into subproblems and to consider the relevancy of information (de Groot, 1968; Sweller, Mawer \& Ward, 1983). A common assumption is that those with more experience will make better decisions. However, in naturalistic complex and dynamic novel situations, to search for a "gold standard" option is often not appropriate (Orasanu \& Connolly, 1993).

To better describe the relationship between experience, recommendations, and strategy use the associations between Time in Service and familiarity with the levels of force protection and mission accomplishment were examined. The association between levels of force protection and mission accomplishment were examined relative to other variables which may be indicative of knowledge about these dimensions: participants' branch, rank, and schooling. Measures of association were calculated to determine if knowledge about the participant's background on these variables would predict which recommendation would be made. Table 6 shows the value of asymmetric Lambda ( $\lambda \mathrm{C} \mid \mathrm{SE})$ associated with the likelihood of an improved prediction of the solution emphasis (SE) given that one knows the participant's demographic information (C). Values of zero were obtained for rank and CAS3 and CGSOC instruction.

Table 6

Association between Demographic Variables and Solution Emphasis

\begin{tabular}{|c|c|c|c|}
\hline $\begin{array}{c}\text { Solution } \\
\text { Emphasis }\end{array}$ & Branch & $\begin{array}{c}\text { Time in } \\
\text { Service }\end{array}$ & Familiarity \\
\hline Force protection & .025 & .010 & .308 \\
\hline Mission accomplishment & .013 & .010 & .154 \\
\hline
\end{tabular}

Note. Predictive value of Lambda varies between 0 and 1 .

These associations suggest that only participants' familiarity with the type of problem provide any predictive ability about their recommendations. Results of confirmatory general linear model analyses using the levels of recommendations as dependent measures and the continuous variables of time in service and familiarity as independent variables showed no relationship between the levels of Mission accomplishment and either time in service or familiarity with the problem. However, parallel analyses using levels of Force protection as the dependent variable revealed a significant relationship, between levels of recommended force protection and familiarity with the problem, $F(3,57)=2.91, M S \mathrm{e}=6.86, p=$ .042 ), but not with time in service. Higher levels of familiarity were related to recommendations that provided for lower levels of force protection (see Figure 3). One possible explanation for this pattern of results could be that participants' different experiences with similar situations allowed them to plan for contingencies to

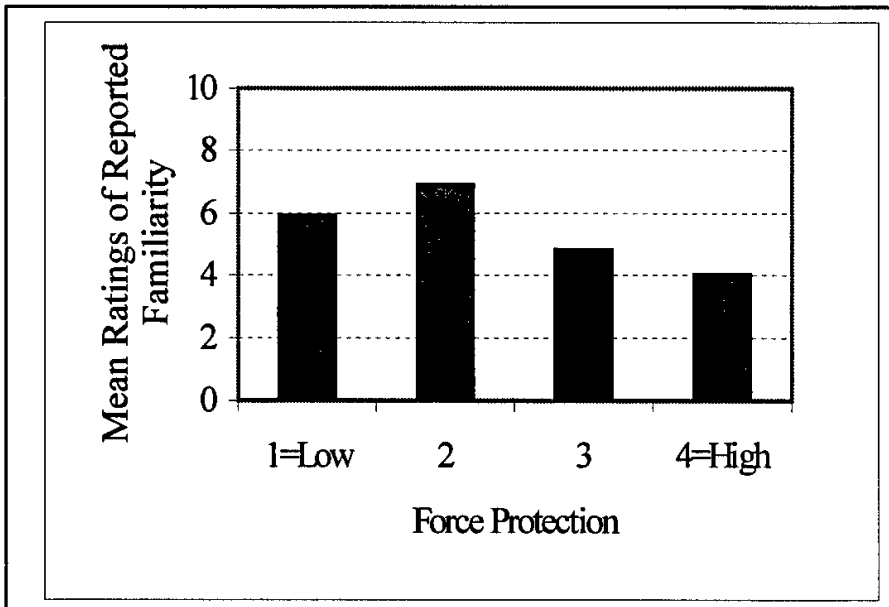

Figure 3. Relationship among recommendation and familiarity. 
compensate for low levels of force protection.

Taken together, these results suggest that experiential characteristics such as one's time in service, rank, or branch do not necessarily predict how he or she will go about solving problems. Further, these results demonstrate evidence that different strategies were associated with making different recommendations, in both specific problems (see results in Pounds \& Fallesen, 1997) and when higher conceptual dimensions of problems were considered.

This suggests that research to focus on personal differences rather than training and schooling would pinpoint important influences on problem solving processes. One inference to be drawn from these results is that people may have natural tendencies to solve problems that are not related to instruction. Just what these natural tendencies are is not yet clear. However, the process that one uses to arrive at a recommendation is an important aspect of problem solving and should receive greater attention. Results from the interim report suggest that people may prefer either to rely primarily on what they know about different aspects of the problem or on a procedure but not both.

The challenge for future research will be to further determine what these personal attributes are and whether guidance to emphasize one particular strategy over another would result in different outcomes. These results also suggest that strategy outcomes are mediated by level or type of knowledge, suggesting that training to make an early metacognitive assessment about how much or what one knows about the problem would be useful. Thus, how knowledge was used in conjunction with one particular strategy was examined as an example.

\section{Goal Identification}

One strategy presented to participants for rating was Identified a specific goal. The challenge for problem solvers is to identify which goals are important, how they are related, and what tasks are necessary to achieve them. However, shifting, competing, and ill-defined goals in typical real-world problems make identification, relationships, and tasks more difficult to define (Klein, Calderwood \& Clinton-Cirocco, 1988). Successful management of real-world problems often requires goal formulation and definition (Beckmann \& Guthke, 1995).

Use of this strategy is specified by the schoolhouse stepwise method of problem solving and most participants rated Identified a specific goal as an important strategy in their thinking about the tactical problems (average importance rating of $=4.33 / 5.00$ ). However, not all participants arrived at the same recommendation for solution. Although participants reported using the same strategy, it was possible that different people identified different goals, thus resulting in different recommendations. To clarify this, participants' comments about their goals were examined.

Method and Results

Available transcripts $(n=58)$ were examined for participants' remarks relative to the strategy "Identified a specific goal." These were categorized in Table 7. Following the table is a selection of participant's comments illustrating the diversity of goals, which were identified.

For example, one participant reported his specific goal as: ...to maintain offensive operations, division's main effort to get across. Specific goal is, in my opinion, to get across the bridge to maintain offensive operations. 
Table 7

Participants Reporting a Specific Goal

\begin{tabular}{|c|c|c|}
\hline $\begin{array}{c}\text { Different Specific } \\
\text { Goals }\end{array}$ & Percent & $n$ \\
\hline Secure bridge & 29 & 17 \\
\hline Execute LD & 3 & 2 \\
\hline Spearhead attack & 5 & 3 \\
\hline Cross bridge & 2 & 1 \\
\hline Take assembly area & 29 & 17 \\
\hline Night attack & 2 & 1 \\
\hline With bridge & 9 & 5 \\
\hline without giving away forward position & 2 & 1 \\
\hline Maintain momentum & 2 & 1 \\
\hline Mission & 2 & 1 \\
\hline Force protection & 3 & 2 \\
\hline Hold up/Defense & 5 & 3 \\
\hline Could see no goal & 7 & 4 \\
\hline Total & 100 & 58 \\
\hline
\end{tabular}

Another participant saw the situation differently, reporting that his specific goal was to take the assembly area: "... you had the initial plan that the brigade started you out on, the deliberate attack that was going to start at 4:00. So you had a specific goal when you started out, but things were changing, so you had to redefine your goals."

Others, when asked about their specific goals, replied: "I wish I had a specific goal." and "Now part of this is going to be, if I do go on the assault, or do attack how strong of a resistance do I meet before I decide to pull back and go into defensive. My main goal overall is trying to conserve forces while meeting the raw intent."

Despite the consistency with which they reported using the same strategy, participants were not

consistent in the objects of their stated goals. In other words, the strategy was the same but the goal was different, thus illustrating the interaction between strategies and information use during problem solving. Further, participants not only differed in their goals but also in the level of abstraction at which they were thinking about goals. These comparisons demonstrate how differences between individuals can influence outcomes of strategic processes--in particular, identification of what is relevant for a particular situation. However, it is not clear from this interview data whether the level of abstraction at which one is thinking about the problem influences how strategies are organized and used.

Although it is generally agreed that people who are experienced in a domain have highly organized and abstracted knowledge in memory to draw on and that they employ different strategies than novices (Johnson, 1988; Patel \& Groan, 1991), it has not been clearly determined whether their strategies emerge from the available knowledge base or whether the organization of the knowledge base emerges based on the use of preferred strategies by the individual. What is generally acknowledged, however, is that recognized expertise typically requires at least a ten year time span of study and results from concentrated effort to acquire and understand a domain of knowledge. Despite the recognition that an elaborate base of domain knowledge is necessary for expert problem solving ability in a domain, it is not clear that this also defines the sufficiency of expertise. The nagging question remains: if domain knowledge is necessary for expertise, is it also a sufficient definition for expertise?

An answer to the sufficiency definition might lie in the strategies used when learning new information. Beckmann and Guthke (1995) proposed that knowledge acquisition be examined separately from knowledge application. Perhaps the answer to the relationship between strategy use, information, and expertise lies in this separation. Conceivably, strategies (and approaches) could differ in their usefulness depending on whether the problem solver was acquiring or using knowledge. The strategies typically associated with expertise may be those of knowledge application. For training to meet the challenges of new situations, the strategies of knowledge acquisition might be more important As Holt (1964) noted "The true test of intelligence is not how much we know how to do, but how we behave when 
we don't know what to do" (p. 165). Given the diversity of problems that tactical leaders face, this is a relevant issue. Future research is needed to sort out this question.

\section{Organizing Themes: Beliefs, Attitudes, and Values}

Other higher-order knowledge representations, such as beliefs and attitudes, might also serve as organizers for strategies. People have long been known to hold beliefs, attitudes, and values about their environment. The full effect of these on problem solving has not been clarified. Although this project examined the higher-order constructs of "approaches" and their relationship to problem solving, it is plausible that personal themes provide even more general guidance choosing relevant information and prioritizing actions during problem solving than does the concept of a preferred problem solving approach. For example, consider a company commander conducting a mission. He is suddenly facing an unexpected enemy layout. If he places a higher value on preserving human life than on gaining an objective (belief), he might well elect to find a solution (goal) which preserves the troops rather than gain the objective. In this case, the choice of approach would probably depend on the commander's beliefs, attitudes, and values along with experience in force protection.

In terms of thinking processes, themes acting as organizers may be similar to "attractors" (see Waldrop, 1992) in that they are overarching schema which have high importance to the individual such that they take precedence in thinking and serve as organizers for lower-order schemas and problem solving strategies. They might be so important as to transcend specific situational influences. On the other hand, the use of some types may be more influenced by one's circumstances. Thus, this would help explain how the same or similar sub-schema and strategies could flexibly serve multiple themes for information selection, organization, recognition, etc.

Moreover, the consequences of conflicts between themes during problem solving are not clear. For example, could this result in deeper thinking about the problem, an increase in time needed to solve the problem, or a shift to a different theme to avoid the conflict? Could this affect solution quality? Future studies will have to address these questions. For the present purpose, available transcripts from both personal and tactical problems were examined for the existence of themes.

Method

To investigate this, transcripts of the interviews $(n=181)$ were examined for evidence that participants held general, over-riding themes. A theme was identified when a higher-order value reappeared throughout their discussion of a problem. This method was based on the assumption by that personally relevant information is available in working memory and is accessible for discussion. Each transcript was scanned for early mention of a likely candidate to be classified as a theme. To be considered, a promising, general concept had to appear within the first moments of the discussion and again during the end of the problem's discussion. However, it was not unusual for remarks relevant to the theme to recur periodically throughout the discussion.

Results

Several candidate themes were identified. After all the transcripts were reviewed, excerpts illustrating the themes were compared and grouped under major descriptive headings. (For the examples illustrating both themes and new strategies, multiple excerpts from a participant's transcripts were grouped as one even though they may have appeared at different points throughout the interview.) These were then conceptually grouped using a concurrent classification method and annotated with examples from the transcripts (Table 8). Frequency of each theme is noted based on those that were obviously 
Table 8

Descriptions and Examples of Identified Themes

\begin{tabular}{|c|c|c|c|}
\hline Theme & Freq & Description & Example \\
\hline $\begin{array}{l}\text { Safety } \\
\text { (e.g., force } \\
\text { protection) }\end{array}$ & 20 & $\begin{array}{l}\text { Protection of assets (troops, } \\
\text { resources, maneuver; present } \\
\text { and future) }\end{array}$ & $\begin{array}{l}\text {...So l'd make sure that everyone is on the same sheet...also the } \\
\text { synchronization of making sure that the artillery doesn't land on } \\
\text { these guys, but I got a GPS so I should have an accurate grid, } \\
\text { know exactly where they are. }\end{array}$ \\
\hline $\begin{array}{l}\text { Assumed } \\
\text { control }\end{array}$ & 7 & $\begin{array}{l}\text { Presumes that one dominates } \\
\text { the situation. }\end{array}$ & $\begin{array}{l}\text {...use my mech forces first to maybe attack the assembly area and } \\
\text { use the, this tank force right here as some type of support element } \\
\text { to ensure that I can take the assembly area and then keep one } \\
\text { mech infantry force in reserve and also put this ITB company in } \\
\text { position where they can also support the attack on this assembly } \\
\text { area right here so we can clear that, intermediate objective, so you } \\
\text { get to the bridge. }\end{array}$ \\
\hline $\begin{array}{l}\text { Accom- } \\
\text { plishment } \\
\text { (e.g., of } \\
\text { mission) }\end{array}$ & 6 & $\begin{array}{l}\text { Completion in terms of the } \\
\text { mission, personal goals, or } \\
\text { commander's intent, etc. }\end{array}$ & $\begin{array}{l}\text { I mean, this sounds corny, but I can give up my whole company } \\
\text { but if one squad brought back the guys I was going after then I've } \\
\text { accomplished my mission. }\end{array}$ \\
\hline $\begin{array}{l}\text { Investiga- } \\
\text { tion }\end{array}$ & 6 & $\begin{array}{l}\text { Operating in uncertain } \\
\text { situations to gather more } \\
\text { information. }\end{array}$ & $\begin{array}{l}\text { Everything l'm going to do is try to get more information, because I } \\
\text { don't think at 8:00 at night, and from the indications that the LRSD } \\
\text { are giving the scout platoon, things don't look too good. }\end{array}$ \\
\hline $\begin{array}{l}\text { Obligation } \\
\text { (as part of } \\
\text { a larger } \\
\text { group) }\end{array}$ & 5 & $\begin{array}{l}\text { Awareness that, as a soldier, } \\
\text { one is not acting alone. }\end{array}$ & $\begin{array}{l}\text { But I viewed that as a significant problem to the division. He } \\
\text { probably has to use this same access through here. I wanted to } \\
\text { make sure that I systematically cleared this area so there wouldn't } \\
\text { be a problem for the rest of [the division]. }\end{array}$ \\
\hline Initiative & 5 & $\begin{array}{l}\text { Motivation to go beyond one's } \\
\text { typical responsibilities. }\end{array}$ & $\begin{array}{l}\text { And that's what l'm going to go ahead and do, and if you don't } \\
\text { want me to do that, then you need to stop me. }\end{array}$ \\
\hline $\begin{array}{l}\text { Coordina- } \\
\text { tion }\end{array}$ & 4 & $\begin{array}{l}\text { Keeping the elements of the } \\
\text { situation in synchronization. }\end{array}$ & $\begin{array}{l}\text { because of the sketchy scenario... get all company scouts out as } \\
\text { quickly as possible to keep eyes out in front of the respective lanes } \\
\text { as you're moving fonward. Then like I said, I don't know who's left } \\
\text { and right but I think it's important to key into those guys. }\end{array}$ \\
\hline $\begin{array}{l}\text { Flexibility } \\
\text { (in options } \\
\text { or roles) }\end{array}$ & 4 & $\begin{array}{l}\text { Sees the usefulness of being } \\
\text { in a position that has multiple } \\
\text { possible consequences. }\end{array}$ & $\begin{array}{l}\text { And the only thing I put down in most important is because of it } \\
\text { being very sketchy, we're going to have to break it down into } \\
\text { smaller problems and take them one at a time, instead of just } \\
\text { going head long into one big mess. Just take it a piece at a time, } \\
\text { and work from that piece, trying to be flexible. }\end{array}$ \\
\hline $\begin{array}{l}\text { Prepared- } \\
\text { ness }\end{array}$ & 2 & $\begin{array}{l}\text { Emphasis on being ready to } \\
\text { overwhelm the situation. }\end{array}$ & $\begin{array}{l}\text { Actually, I had said that I had pulled in four personnel to do this } \\
\text { and I still had ten personnel in the field so I actually had more. I } \\
\text { could have pulled in more labor to do it. It was just a matter of } \\
\text { how much of it did I want to leave the actual tactical mission in the } \\
\text { field. How much did I want to leave it open? }\end{array}$ \\
\hline Disruption & 2 & $\begin{array}{l}\text { Shaking up the status quo, } \\
\text { whether in one's own or } \\
\text { enemy thinking. }\end{array}$ & $\begin{array}{l}\text { And usually my job is to argue with him if I don't agree with it, or if I } \\
\text { don't think I can accomplish his mission with keeping people alive. }\end{array}$ \\
\hline Caution & 2 & Consider the high level of risk. & $\begin{array}{l}\text { I think there would be too much damage, too much risk involved. } \\
\text {... and it's overly optimistic not to think someone's going to get hurt or } \\
\text { some kind of property get damaged, especially if we start flying } \\
\text { Apaches around and they drop anything in the area... Someone } \\
\text { outside that compound might be hurt, and if that was unacceptable } \\
\text { then l'd ... }\end{array}$ \\
\hline $\begin{array}{l}\text { People } \\
\text { focus }\end{array}$ & 1 & $\begin{array}{l}\text { Emphasis is on personal or } \\
\text { interpersonal states or } \\
\text { relationships. }\end{array}$ & $\begin{array}{l}\text { I didn't really think that people were dying over there but what I did } \\
\text { was put myself in a real situation. Would I sit here and watch a } \\
\text { satellite dish while my buddy is screaming over there? I said no. } \\
\text { So I said no, let's go. It's a lot more fun than sitting here and } \\
\text { watching, too. }\end{array}$ \\
\hline Retaliation & 1 & $\begin{array}{l}\text { Evening the score through } \\
\text { counterstrike or punishment. }\end{array}$ & $\begin{array}{l}\text { The enemy at that point, they thought they could get away with } \\
\text { firing on the aircraft. }\end{array}$ \\
\hline
\end{tabular}

apparent from the transcripts. Frequencies were not intended to represent the absolute proportions of occurrence of the theme in the sample of participants. 
If themes are higher conceptual structures, they may be more useful as the situation becomes more familiar. Studies of expertise have concluded that experience is associated with the greater use of abstract concepts (Patel \& Groen, 1991).

If recurring themes were pervasive and if each person can hold multiple themes from which one or more are applied to one situation, it is also plausible that these themes would in some situations conflict, being inconsistent with one another in a given situation. For example, some participants considered safety vs. security and force preservation vs. mission accomplishment. One could also envision situations where others would compete: being prepared vs. taking initiative, retaliation vs. caution, flexibility vs. coordination, etc. The conflict in themes (or goals) is part of the uncertainty that requires problem solving.

The consequences of conflict are not known, although one might speculate that this would disrupt efficient problem solving. In other situations, themes elicited by the situation may be compatible, having different consequences, such as streamlined problem solving.

\section{Identifying Natural Reasoning Strategies}

In addition to identifying other ways to conceptualize how strategies are organized while problem solving, an important goal of the present research was to identify new reasoning strategies used during the task. The tactical problems (see Pounds \& Fallesen, 1994 for a description) were chosen so that the problems in accomplishing the missions would be more like those that participants would confront in a battlefield situation.

The strategies employed in the card sort task were drawn heavily from existing literatures (see Pounds \& Fallesen, 1994), most of which studied problem solving and decision making from a classical procedural perspective derived primarily from economic theories. This perspective has, for the most part, ignored naturalistic tasks and processes. Thus, this analysis of the transcripts aimed to identify new strategies, which might be associated with naturalistic thinking processes. In some cases, the strategy was similar to existing definitions but differed in important ways, and so was included. For example, the strategy of making trade-offs has long been recognized. However, in the protocols, trade-offs were often made between abstract concepts or principles rather than specific characteristics of the situation. A strategy similar to chunking, which has long been appreciated as a way to unitize bits of information to increase efficiency of memory, was identified. In the protocols, a type of clustering occurred more as an information-organizing device. By grouping on a similar dimension, many situational elements (e.g., installing radio equipment in HMMWVs - high mobility, multipurpose wheeled vehicles) could be considered as a macro-unit of information to think about the problem. At the same time these macro-units could be compared on their dimensions relative to each other and also relative to other information.

Method

Available transcripts of the two tactical problems and participants' remembered problems were examined $(n=181)$. When the participant's comments reflected that he or she was considering various aspects of the problem or particular content, that section was compared to processes representing strategies already identified from the literatures. Relationships and attributes for the particular concept of interest were noted. If the section was judged to be different from those strategies that had already been catalogued from the literatures, it was kept and considered for inclusion as a "new" strategy. Strategies were then sorted into similar groups using the concurrent classification method. 
Results

Table 9 lists 22 strategies that were identified from the transcripts, with a brief definition and frequency of occurrence. Appendix A provides examples from the transcripts for each new strategy. Noted frequencies of strategies reflect those that were obvious in the transcripts rather than any distribution in the sample.

These reasoning strategies could be used to clarify and elaborate the processes of recognition, dominance, mental simulation, etc. by detailing how these specific strategies are used as part of the more general approaches. Naturalistic models have primarily focused on examining how decision makers develop one option using recognition processes. Although this is characteristic when the problem solver is familiar with the domain, the data from the interim report showed that in unfamiliar problems, a dominance process of attribute comparison was frequently used. While some people do just develop one option, natural strategies for multiple option comparisons based on attribute evaluations have not been clarified. One likely candidate for future examination of multiple option comparisons in naturalistic situations is comparison testing.

\section{Other Possible Organizers}

One influence on problem solving which has received little research attention is the use of figurative language, such as idioms, parables, and folktales, while thinking. Figurative language conveys cultural guidance and takes the form of a rule that is not meant to be interpreted literally. Rather, they represent knowledge and experience summarized as one expression. Because some of the participants used such 'sayings' during their interviews, these were also noted.

- "fall together like a puzzle"

- "can't sweat the small stuff"

- "putting all your eggs in one basket"

- "kill two birds with one stone"

- "not to get wrapped around the axle"

- "it may be Chicken Little"

- "DOS" Situations change. We call it DOS: depends on situation.

- "the more we have, the stronger we are"

- "stop the bleeding"

- "blow them over"

- "run through them"
- It's easier to ask forgiveness than permission.

- time is now

- "open up a whole new can of worms"

- "I like the smell of time...."

- It's a "Golden Escape" or "Golden Bridge."

- "Get that high ground; keep going all the way to Berlin."

- "grab them by the nose and kick them in the ass"

- "Silence is consent."

The influence of figurative language on problem solving is open to speculation. The phrases could provide mental guidance for the problem solver during the solution process or they could be used by the problem solver to facilitate communication of abstract ideas to others. If so, the source, form, and consequences of such folk guidance when used by tactical leaders are not clear. Future research should clarify these questions. 
Table 9

Natural strategies, descriptions, and frequency (number of cases in which the strategy was identified)

\begin{tabular}{|c|c|c|}
\hline Strategy & Definition & Frequency \\
\hline \multirow[t]{2}{*}{$\begin{array}{r}\text { Organizing } \\
\text { understandings }\end{array}$} & $\begin{array}{l}\text { Simplify the situation by combining information based on } \\
\text { what is relevant or important to the situation }\end{array}$ & 20 \\
\hline & $\begin{array}{l}\text { By controlling amount } \\
\text { By comparing } \\
\text { By typecasting } \\
\text { By saving resources } \\
\text { By avoiding uncertainty }\end{array}$ & $\begin{array}{l}6 \\
6 \\
6 \\
2 \\
1\end{array}$ \\
\hline Comparison testing & $\begin{array}{l}\text { Considering some dimension of the situation in different ways } \\
\text { to evaluate the implications of each on the situation }\end{array}$ & 14 \\
\hline \multirow[t]{2}{*}{ Information credibility } & $\begin{array}{l}\text { Consider the source of the information when assessing the } \\
\text { quality of the information }\end{array}$ & 11 \\
\hline & $\begin{array}{l}\text { Of the person } \\
\text { Of the role } \\
\text { Of the medium }\end{array}$ & $\begin{array}{l}6 \\
4 \\
1\end{array}$ \\
\hline Monitoring knowledge & $\begin{array}{l}\text { Assessing the state or quality of understandings about the } \\
\text { information being used. }\end{array}$ & 10 \\
\hline Rule use & $\begin{array}{l}\text { Simplify the situation and solution by relying on automatic } \\
\text { behaviors or standard operating procedures }\end{array}$ & 8 \\
\hline Predict a future state & $\begin{array}{l}\text { Characterize a particular point in time so that its implications } \\
\text { can be evaluated, used in mental simulations, etc. }\end{array}$ & 8 \\
\hline Goal comparison & $\begin{array}{l}\text { Resolving conflicts between goals by evaluating the attributes } \\
\text { and implications of each goal. }\end{array}$ & 8 \\
\hline Goal negotiation & $\begin{array}{l}\text { Consider the attributes and implications of goals to } \\
\text { accomplish all, resolve incompatibility, or balance outcomes. }\end{array}$ & 5 \\
\hline Goal questioning & $\begin{array}{l}\text { Ask whether the held goal is still appropriate given a change } \\
\text { in the situation }\end{array}$ & 2 \\
\hline Goal prioritization & Order goals in term of their importance to the situation. & 2 \\
\hline Goal choice & Select a goal for current action from among identified goals. & 1 \\
\hline Considering others' goals & $\begin{array}{l}\text { Considering the motivation and intent of others in the } \\
\text { situation (enemy, commander, etc.). }\end{array}$ & 1 \\
\hline $\begin{array}{r}\text { Use situation constraints } \\
\text { to determine priorities }\end{array}$ & $\begin{array}{l}\text { Shape the attributes of the solution around the limitations of } \\
\text { the situation. }\end{array}$ & 3 \\
\hline $\begin{array}{r}\text { Anchoring on information } \\
\text { from authority }\end{array}$ & $\begin{array}{l}\text { Staying with the last concrete information or mission in the } \\
\text { face of new uncertainty }\end{array}$ & 7 \\
\hline $\begin{array}{r}\text { Compensating for missing } \\
\text { information }\end{array}$ & $\begin{array}{l}\text { Handle uncertainty by making up for missing information } \\
\text { using other means, (e.g., flexibility, use more force, etc) }\end{array}$ & 7 \\
\hline $\begin{array}{r}\text { Grouping information } \\
\text { (clustering) }\end{array}$ & $\begin{array}{l}\text { Creating subgroups of information based on a superordinate } \\
\text { attribute that is related to and facilitates reaching the goal }\end{array}$ & 4 \\
\hline $\begin{array}{l}\text { Infer new information } \\
\text { from missing information }\end{array}$ & $\begin{array}{l}\text { Making assumptions about a situation based on information } \\
\text { that is not present but that ordinarily would be expected. }\end{array}$ & 2 \\
\hline Reinterpretation & $\begin{array}{l}\text { Taking a new perspective on the problem or changing one's } \\
\text { understanding of the situation }\end{array}$ & 5 \\
\hline $\begin{array}{r}\begin{array}{r}\text { Considering situational } \\
\text { error }\end{array}\end{array}$ & $\begin{array}{l}\text { Recognizing that variability exists in the environment and its } \\
\text { implications }\end{array}$ & 4 \\
\hline Estimation & $\begin{array}{l}\text { Using an attribute of the situation (such as size) to assign } \\
\text { resources }\end{array}$ & 4 \\
\hline $\begin{array}{r}\text { Feedback-seeking } \\
\text { actions }\end{array}$ & $\begin{array}{l}\text { Initiating a behavior to gauge the results and to use this as } \\
\text { information for future behavior. }\end{array}$ & 4 \\
\hline Abstract trade-offs & $\begin{array}{l}\text { Making qualitative comparisons between beliefs, goals, } \\
\text { options, etc. }\end{array}$ & 3 \\
\hline
\end{tabular}




\section{Conclusions}

The intent of this research project was to describe how tactical leaders actually go about problem solving. Building on the results from phase one, phase two of this research demonstrated that the Army's tactical leaders face diverse problems. Further, they are likely to face problems for which they have received little or no advance preparation. The findings from this report support the notion that the thinking processes of problem solving are important concerns for training tactical decision makers and thus deserve more research attention. Lopes (1987) argued that the strategic processes that one engages to find a solution must be understood before enhancements to those processes can take place. This report goes further by suggesting that both process and types of content must be considered.

\section{Approach}

Results demonstrated that tactical leaders did not share a common view about how to go about solving complex problems. Rather than sharing a common problem solving approach, they demonstrated how individual differences in background and strategy use can affect recommendations for courses of action. However, results from phases one and two suggest that people prefer to use either an attributebased or a process-based approach. Few participants tended to switch approaches between problems. Rather, most people preferred to stick with the same approach for both tactical problems. Thus, one's personal approach to problem solving may be more like a general personal preference and less like a chosen technique.

Participants may have been exhibiting natural tendencies, which are not related or responsive to military training or schooling. Thus if both process and content are indeed important, then the challenge for future research will be to identify the determiners and consequences of these preferences. The present research demonstrated evidence that this may be the case. If the preferences are ultimately shown to result in poor performance outcomes, then interventions and enhancements will have to be devised. The challenge will be to identify ahead of time exactly what will be categorized as "poor performance" in a domain where the notion of a "right answer" is not appropriate.

\section{Problem Dimensions}

Participants did not have a common perspective about essential dimensions of a problem. For example, participants differed in the ways and degree to which they considered to protect their forces. Further, they differed in how they redefined and planned for accomplishing the missions. Thus, one should expect that they would also make different recommendations. Also, combinations of problem solving strategies were associated with different recommendations. The extent that the use of one strategy or another directed thinking towards a particular recommendation is not clear. Research manipulating focus and strategy use should be able to answer this question.

Goals

Participants did not share the same goals within the same situations. Analysis of individual differences in identification of a specific goal illustrated that similar strategy use combined with dissimilar content can result in a diverse variety of identified goals. This implies that merely relying on instructions to use a particular strategy or procedure for problem solving does not guarantee either uniform or satisfying outcomes.

Rather, two different problem solvers could "plug in" his or her own unique experiences into the same strategy during thinking, possibly resulting in different outcomes. Take, for example, an example from algebra. If two people are assigned to solve the equation, $\mathrm{A}$ combined with $\mathrm{B}=\mathrm{C}$ where $\mathrm{C}$ is known to be equal to 100 , many combinations of groupings for variables $\mathrm{A}$ and $\mathrm{B}$ can fill the requirement: 
$A+B=100, A(B)=100, A / B=100$. Outcomes depend on both the chosen procedure and the values assigned to A and B. Similarly, given the outcome of spearheading the division in the next day's effort, there are many ways to accomplish this, depending upon the experience, knowledge, etc. of the decision maker who is charged with organizing his battalion assets toward that goal. Thus, implicit guidance for everyone to use the same problem solving strategies would seem to be counterproductive given that everyone has different experiences to bring to the task. Given this, teaching a one-size-fits-all problem solving template to use for all problems seems counterproductive, that is, not acknowledging the possible variability of $A$ and $B$ in the possible situations. Besides giving the illusion of problem solving precision, it risks forcing one to attend to the method rather than the substance. To carry the combinatorial analogy a bit further, an alternate approach to enabling better problem solvers would be to help problem solvers understand they derive the As, Bs from their experiences and how they combine them. Training could then be based on the understanding of naturalistic preferences, rather than outside them.

Naturalistic Strategies

Promising strategies were identified for future investigation as "naturalistic" processes. Many appeared to be used to reduce large amounts of information to manageable amounts and to resolve conflicts between information. For example, two candidates were clustering information and comparison testing between alternatives. These strategies appeared to facilitate manipulation of information without demanding quantitative comparisons. Other strategies appeared to aid evaluation of information quality, such as considering the source of the information. For example, information that could be graphically illustrated by the person delivering it had more credibility than if it had merely been verbally reported, but reports by scout platoon leaders had high credibility because of their assumed expertise in their job. Strategies to resolve conflicts among goals, missions, etc. were also important. For example, one participant had to find a way to protect his troops while still keeping everyone awake and moving.

Using these findings to explore the natural strategies that were identified and to elaborate on their conditions of use will extend findings from the artificiality of laboratory tasks to naturalistic situations. Identifying and defining natural strategies aids in developing richer explanations of real-world problem solving.

Themes as Organizers

Overarching themes running through the transcripts were identified. These structures were likened to schematic organizations of knowledge representing one's beliefs and values about the world. Because strategies at the level measured by the present study appeared to be flexibly applied based on person and problem characteristics, it may be that higher-order knowledge structures serve as organizers for strategies. If this is demonstrated by future research to be the case, then problem solving enhancements can also be developed at this level. Personal development exercises could be developed to assist military leaders in identifying their basic beliefs and values and how these are manifested in their problem solving. For example, when one forms a belief about a situation and begins to think about the problem from a particular point of view, the belief can drive thinking about the problem, as illustrated by the following excerpts.

Our decision was that we tell the CG that it's a non-doctrinal array, we still did not believe that he would assume offensive operations in the near term, and [we believed] that we needed to stay with the plan until we got more information.

If they wanted to kill him, then clearly it's not going to be Captain Jones [referring to self] that's going to get the mission to take this guy out. I'm going to set up some type of perimeter. The Special Forces guys are going to go in there and take him out with a guy that's a member of the 
Security Council. So I'm going to make the assumption that they're not going to kill the Ambassador if they're attacked. So I land my forces at some point, as I said, back at here.

To generalize across problem situations, the tactical problems were examined for associations between particular strategy use and the recommendations made based on higher-order concepts of the problems. Two higher order concepts were force protection and mission accomplishment. These two themes are often at odds with one another. To accomplish a mission through force a commander inherently puts his force at risk. Too much conservative emphasis on force protection and the accomplishment of mission is at risk. Results demonstrated that when analyzed at these levels different patterns of strategies were associated with different recommendations. What is not yet clear, however, is whether the differential use of a strategy implies that the associated recommendation will follow from its use. An alternative explanation might be that once the problem solver focuses on a particular dimension of the problem, e.g., protection of forces, the strategies used then follow from that initial adoption.

One pervasive characteristic of more and more military operations is that they occur in dynamic situations, often with varying levels of uncertainty, having multiple players, and conflicting goals. What was not clarified in the present paper is the nature of the consequences when these characteristics exist simultaneously. For example, if the tactical commander held competing goals of force protection and mission accomplishment, how is this conflict resolved, if it is resolved at all? Complications might follow from such a situation, such as time delays to resolve the dilemma, jumping prematurely to favor one dimension over the other, etc. Thus, attending to conflicting concepts could have important tactical consequences.

\section{Recommendations}

"In principle, intuitive experiential linkings may at any time become knowledge ('knowing that', in addition to 'knowing how'), namely, at that moment when the subject becomes fully aware of them." (de Groot, 1968, p. 147).

It is likely that personal preferences are naturalistic to the extent that they have developed through past successes and failures during problem solving experiences. Therefore, since research has demonstrated that military leaders tend not to use doctrinally mandated decision techniques, particularly in dynamic situations, the question becomes one of how to best enhance their naturally occurring approaches and strategies during subjective assessments. For example, one participant pointed out that it was impossible to quantify information, such as national attributes of foreign countries, to use in calculations. "Any numbers that you come up with to put into a computer would be entirely bogus before you even started." Another participant pointed out that it was not possible for him to quantify the concept of "military bearing" for subordinates' evaluations. The only quantifiable attributes for the ratings were weight and PT [physical training] score. The remainder is based on subjective assessment. As he noted, "You can be in good shape and not overweight and still not have military bearing." These comments suggest that current methods provide little assistance in making subjective judgments. A review of the problems illustrated in the Introduction would support this observation.

As demonstrated by the problems that participants remembered from their past experience, military leaders face a variety of unusual and novel situations which their trainers may have not foreseen, and yet, they must figure out some way to cope with the situations and to avoid negative consequences. In many cases, they reported that they relied on knowledge from other situations that were different but similar in some respects. For example, one participant reported a training situation where he used personnel in nonstandard positions to accomplish his training objectives and maximize fire power. 
In the back of my mind I recalled that it had worked in the ceremonial situation and why couldn't I apply the same... same factor to this situation where I was actually going out to live fire. Obviously the risk was a little bit greater, in the situation I was confronting, you know, the worst thing that could have happened in the ceremony was someone could have tripped and made a spectacle during the ceremony or, you know, one of the [guns] that fired early. In the live fire exercise that I was going on, certainly if something had happened where a round had left that impact area or something....

Based on the analyses of the interviews, three recommendations follow. Two focus mainly on opportunities for officers' self-insight and one focuses on using knowledge. The following recommendations focus on methods which could assist in situations were subjective judgments are required and when officers face novel situations, particularly when time is short and the stakes are high.

\section{Self-development Using Intelligent Tutors}

One candidate for enhancement would be problem solving exercises so problem solvers would be more attuned to their strategy use and consequent effects on performance. Anecdotal evidence from the interviews and transcripts suggested that this would not be an aversive experience. Rather, participants made comments to the effect that the thinking task "stirred up my brain cells" and "this is good mental gymnastics." The goal would be to mimic the problem solving and strategy elicitation processes of the original interviews but, by using available technology, allow the participant to interact with an intelligent tutor that would guide him or her through the strategy elicitation process. In this way, the participant's thinking could also be guided to particular areas for further consideration. Different dimensions of each strategy could be elaborated. For example, when participants considered the accuracy and reliability of information, oftentimes what they were really assessing was credibility of the source of the information rather than the information itself. Concurrently, likely points where one's thinking method would go astray could be highlighted. Take, for example, a commander who implements a plan based on new information brought by his scout. Does he question the information or does he act because he trusts the scout's ability, because the information is consistent with what is already known, or because it is expected? Officers could be encouraged to examine the bases for the their judgments.

Particular strategy use was associated with both levels of familiarity and with different dimensions of the problems. This was taken as evidence that strategies are flexibly combined to meet the needs of the current situation based on characteristics of the problem and of the problem solver. However, strategy use was also mediated by the content applied to it by the participant. Thus, once one's preferred strategy was identified, metacognitive exercises could assist by prompting one to check for appropriateness. For example, during a training session, if the participant judged that a problem called for a solution that should meet particular criteria, then the criteria could be validated before continuing. Techniques such as these would probably be more appropriate as self-paced tools rather than training per se because of motivational considerations and because they have been demonstrated to be more effective if practiced before they are needed.

\section{Self-development through Self-insight}

If one's overarching beliefs and values do indeed serve as organizers for lower-order strategies during problem solving then performance advantage may accrue if one becomes conscious of one's beliefs as they are made explicit during problem solving. For example, current experimental designs exist which can reveal how one uses certain pieces of information over others. By having the participant respond to manipulated variations on scenarios, his or her "policy" for problem solving can be elicited and reflected back to the participant as feedback. By incorporating this with existing technology, the problem solver would have access to immediate, visual feedback about his or her decisions. This would prompt self-reflection and possibly adjustment of one's problem solving processes. The following 
exchange between an interviewer (Exp) and a participant $(\mathrm{P})$ is an excerpt illustrating the process of selfinsight.

In the following example, the participant describes his process of trying to update his own information while forgetting about the task of remaining coordinated with division units. While being focused on meeting his line of departure for the morning kick-off, he verbalizes a self-understanding about how easy it would be to forget his role as part of a larger picture.

Exp: Explain to me a little bit what you meant by developing the situation.

P: My eyes forward are my scouts. They have already told me that the situation is not as I had perceived it moving up there. So I will immediately send them up forward and say, look, let me know what's up there so I can develop the situation. What I need to do, what I need to send forward. Any enemy that they saw, they would have priority.... Let them try to... not to engage, but I would just send them up. I don't want to be blind. I want to develop the situation. As far as on the ground that's when you ...commander co-located... on the move and ...just try to get a picture of what's out there. Is this an isolated push by the enemy? Are they doing a coordinated attack across the whole entire river? Are they trying to beat us to the punch? Where ...originally and where are these guys at? Who's to my left and right. I should know that but behind enemy lines a lot of times we forget that, you have to remember your coordination, you know, it's always past your $L D$, it seems like it's important.

Exp: Why does it get forgotten?

P: Because you get that false sense of security, I guess. You always, ... I guess... for an operation like this, as a brigade commander, I can tell you right now, I would probably ... but you just might not be set up to get the whole brigade across this one bridge if you had to. I think we kind of get lost in the: -- well, the battle doesn't start 'till we hit the river. And that's not always true but this could happen. All of a sudden we get up there and the river is supposed to be secure and you definitely want to know who's to your left and right then because if it's not friendly then there's the possibility you might have empty spaces and you could be flanked very easily. And the reason we forget that is because as soon as the battle starts we're going across the LD, I mean, generally speaking.

Exp: Interesting observation.

P: So, that's kind of what I'd do....learned something.

Exp: Did you say you learned something?

P: Sure. I could see, if something starts happening, I could just see how brigade--I mean, I don't want to talk bad about my brigade-- but in any area, you get lulled into a sense of security, and you've got to maintain that coordination. You might have saved the whole brigade.

Exp: No, but maybe you will.

Using Existing Knowledge Efficiently and Effectively

Participants appeared to prefer either an attribute-based approach or a process-based approach, but this preference was influenced by their familiarity with the problem. Given that with increasing familiarity and experience comes the ability to recognize a good solution, how can knowledge also be 
leveraged when familiarity and experience are low relative to the problem? That is, what recommendations can one make to help those faced with novel problems, high stakes consequences, and little time?

The recommendation is to exercise military leaders in techniques to apply what they already know to novel situations. When faced with the hostage rescue problem, many participants declared that they had no training in that type of problem, that it was a mission for Special Forces or Rangers, at least. Nevertheless, when pressed for a recommendation, they were able to generate one. However, the analyses of force protection and mission accomplishment showed that some participants ignored or made unwarranted assumptions about the enemy reaction forces. For example, some participants likened the hostage rescue scenario to a raid or a MOUT operation. The transcripts could be examined to determine if those who classified the problem as a certain type treated these abstract problem dimensions differently and, if so, how. For example, did the participants who framed the hostage problem as a raid tend to consider the capabilities of the enemy reaction force differently than those who treated the scenario as a MOUT operation? If one had no knowledge of either raids or urban terrain operations, would analogies from other (i.e., non-military) situations be useful? Whether they would improve with assisted instruction in methods to transfer knowledge across domains or situations is a question for future research.

Effective transfer of training to enable creative problem solving has been demonstrated to depend on one having reliable mental models of the situation (Mayer, Bayman, \& Dyck, 1987). However, other research has shown that novices in a domain tend to focus on the surface, or superficial, information (Patel \& Groen, 1991). Thus the challenge is to develop one's strategies for developing a workable understanding of the situation. Several possibilities exist. One might focus on extracting the essentials from novel situations. One could also focus on identifying important differences between the known and the new situations.

In sum, today's military leaders are being exhorted to do more with less. One means to this end is to encourage development of powerful and adaptive thinking skills. As one participant in the interviews observed:

I studied a lot of military history and of course we have all used the example of Bastogne where the $101^{\text {st }}$ Airborne was surrounded in 1944 and the cooks and medics and supply folks found themselves manning front armed positions and defending the government tanks and things like that., So it's always been in the back of my mind that versatility was probably one of the strengths of the American soldier and something the command should capitalize on. 
References

Beckmann, J. F., \& Guthke, J. (1995). Complex problem solving, intelligence, and learning ability. In P. A. Frensch \& J. Funke (Eds.) Complex problem solving. The European perspective. Hillsdale, NJ: Erlbaum.

de Groot, A. D. (1968). Thought and choice in chess. In P. Wason \& J. P. Johnson-Laird (Eds.), Thinking and reasoning. Baltimore, MD: Penguin.

Fallesen, J. J. (1993). Overview of Army tactical planning performance research (Technical Report 984). Alexandria, VA: U.S. Army Research Institute for the Behavioral and Social Sciences. (AD A273 273)

Headquarters, Department of the Army. (1997). Staff organization and operations. Field Manual 101-5. Washington, DC: Author.

Holt, J. (1964). How children fail. New York: Dell.

Johnson, E. J. (1988). Expertise and decision under uncertainty: Performance and process. In M. T. H. Chi, R. Glaser, and M. J. Farr (Eds.), The nature of expertise. Hillsdale, NJ: Erlbaum.

Klecka, W. R. (1980). Discriminant analysis. Newbury Park: Sage.

Klein, G. A., Calderwood, R., \& Clinton-Cirocco, A. (1988). Rapid decision making on the fire ground (Technical Report 796). Alexandria, VA: U.S. Army Research Institute for the Behavioral and Social Sciences. (AD A199 492)

Lopes, L. (1987). Procedural debiasing. Acta Psychologica, 64, 167-185.

Mayer, R. E., Bayman, P., \& Dyck, J. L. (1987). Learning programming languages: Research and applications. In D. E. Berger, K. Pezdek, \& W. P. Banks (Eds.), Applications of cognitive psychology: Problem solving, education, and computing. Hillsdale, NJ: Erlbaum.

Orasanu, J. \& Connolly, T. (1993). The reinvention of decision making. In G. A. Klein, J. Orasanu, R. Calderwood, and C. E. Zsambok (Eds.), Decision making in action: Models and methods. Norwood, NJ: Ablex.

Patel, V. L., \& Groen, G. J. (1991). The general and specific nature of medical expertise: A critical look. In K. A. Ericsson \& J. Smith (Eds.), Toward a general theory of expertise. New York: Cambridge University Press.

Pounds, J., \& Fallesen, J. J. (July, 1997). Problem solving strategies of mid-career Army officers: Identification of general and specific strategies (Research Note 97-21). Alexandria, VA: Human Resources Research Organization. (AD A335 891)

Pounds, J., \& Fallesen, J. J. (1994). Understanding problem solving strategies. (Technical Report 1020). Alexandria, VA: U.S. Army Research Institute for the Behavioral and Social Sciences. (AD A290 350)

Shanteau, J. (1992). Competence in experts: The role of task characteristics. Organizational Behavior and Human Decision Processes, 53, 252-266. 
Sweller, J., Mawer, R., \& Ward. M. (1983). Development of expertise in mathematical problem solving. Journal of Experimental Psychology: General, 112(4), 639-661.

Tabachnick, B. G., \& Fidell, L. S. (1989). Using multivariate statistics (2nd edition). New York: HarperCollins.

Waldrop, M. M. (1992). Complexity. The emerging science at the edge of order and chaos. New York: Simon \& Schuster. 


\section{APPENDIX A}

Summary of Experimental Method

Data were collected in individual sessions conducted by one or the other of the authors. Participants were obtained at four troop installations through coordination with Forces Command. The 82 participants represented a range of ranks and experience. They were company and field grade officers primarily from the combat arms branches.

Each participant went through a series of experimental procedures limited to a three-hour session. First they provided descriptive information on themselves on a demographic questionnaire. Next they indicated what proportion of time they used each of four problem solving approaches (see attachment

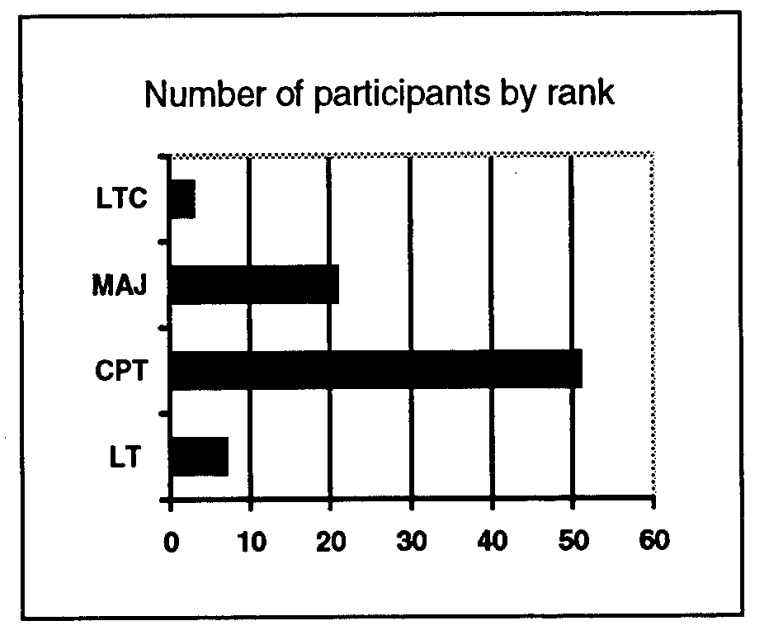
1). These approaches represented ways of thinking that either conformed to formally taught ways or informally acquired ways. The formal ways followed the procedural approach (e.g., Student Text 101-5, 1994) and decision analytic approach (e.g., Anderson et al., 1991). The informal approaches included a recognition-based approach (Klein, 1989) and a dominance approach (Montgomery, 1989).

Participants were then interviewed about a critical problem from their own experience. Audio recordings were made of the story they told. After describing the sequence of events in that incident, they sorted through note cards with the problem solving strategies listed on them (see attachment 2). The strategies were taken from Pounds and Fallesen (1994) who reviewed the problem solving literature and identified 66 problem-solving strategies. This set of 66 was pared down to a set of 48 for data collection. On the first pass through the strategies, participants sorted whether they thought they had used the particular strategy or not. They made a second pass through the set of used strategies to indicate how important each strategy was for that problem. For the most important strategies they explained how the strategy played a part in their problem solving. The participant also answered questions about confidence in their solution, familiarity with that problem, the importance of the problem, the amount of time available to think about the problem, and the amount of thinking effort required to resolve the situation. The influence of these situational factors was recorded on Likert response scales.

This procedure was repeated for two problems given to the participant. In one problem the participant had to role-play an infantry company commander who was unexpectedly given a rapid response mission to rescue an American ambassador from his captors. The experimental procedure was repeated with think-aloud problem solving, approach and strategy ratings, and situational influence ratings. In the second problem, the participant had to role-play a battalion commander who headed up an armored task force. In this scenario the battalion has just received news of an unexpected enemy in the assembly area that they were moving towards and at a bridge that they expected to be held by friendly forces.

The audio recordings were transcribed so qualitative analyses of solutions could be done and content analysis could produce identification of new problem solving strategies and decision themes. 


\section{Attachment 1 to Appendix A}

\section{Definitions of Approaches}

Note that the following definitions were given to participants without the identifying labels.

Analytic: Always generate options systematically, identify criteria for evaluating these options, assign weights to the evaluation criteria, rate each option on each criterion and tabulate the scores to find the best option. Use probability and utility to evaluate alternatives and to calculate possible outcomes. The alternative with the highest outcome is selected.

Procedural: Clarify the situation and gather information without making judgments about it. Identify several alternative solutions. Do a complete analysis of the merit of each alternative before comparing them to one another. Select the best alternative based on the results of the analysis. Implement the solution If the chosen alternative does not work, begin the process of selecting alternatives again.

Recognition: The problem is recognized as familiar. If the situation is very familiar, then a familiar solution may be recognized. Consequences of using the usual solution are imagined to identify pitfalls. If unworkable, then an alternative is developed based on what goals are feasible, what information is important, what to expect next, and what actions are typical in this situation.

Dominance: A promising alternative is identified and the others that have no chance of becoming the best overall are discarded. Determine whether the promising alternative has any disadvantage compared to other alternatives or to some other criterion. If it doesn't have any disadvantages it is chosen. If it does, then information about the alternative's advantages and disadvantages is reconsidered. Upon reconsideration, that alternative is discarded and the process repeated. 
Processing Strategies

Thought of similarities between the information in this problem and what was already known from past experience.

Thought of differences between the information in this problem and what was already known from past experience.

Deconflict information.

Thought in terms of if-then thoughts. For example, if the weather is bad then an alternate route is needed.

Determined parts of the plan that would be prone to flaws.

Considered what information was missing and its implications.

Looked at the problem in terms of a story to develop a fuller understanding.

Considered the solution in terms of a story to develop a fuller understanding.

Restated the problem by visualizing or drawing.

Restated the problem in different terms by looking at it as a different type of problem. For example, an offensive problem was relooked as a defensive problem.

Broke the problem into smaller problems.

Looked at the big picture before the details.

Considered details before the big picture.

Kept the set of things to think about as small as possible.

Imagined the best outcomes.

Imagined the worst outcomes.

Spent time considering various perspectives on the situation.

Identified a specific goal.

Identified problems in accomplishing the goals.

Wrote down everything that I knew about the problem.

Identified facts.

Identified assumptions.

Used specific and precise comparisons.

Used general and approximate comparisons.

Identified information that was unusual.

Considered the reliability of information.

Considered the accuracy of information.

Considered the relevancy of information.

Suspended judgment about possible alternatives until all the information was examined.

\section{Choice Strategies}

The best option had to meet certain required criteria.

The best option should have met certain desired criteria.

Some options were eliminated before comparing options.

More than one option was found to be acceptable.

Acceptable options were reexamined to see if one had more important characteristics than another did.

An option was selected if it met my own internal standards.

An option was selected if it met standards specified by others.

Chose the option that had at least one important characteristic.

Chose the option that was better than all the others on one important characteristic.

An option's disadvantage was considered important only when it was a large disadvantage.

Trade-offs were made between an option's advantages and disadvantages.

Options were judged qualitatively, for example, good, bad, acceptable, etc.

Options were evaluated using quantitative (numerical) assessments.

Used a screening technique to select options for further consideration.

The option that had occurred most often in the past was chosen.

The solution that had worked most often in the past was chosen.

The option that was most attractive on the most important characteristic was chosen.

If the proposed solution was acceptable, no other solutions were considered.

Kept the set of things to think about as small as possible. 


\section{APPENDIX B}

Natural Strategies, Definitions, and Examples (associated with Table 9)

\begin{tabular}{|c|c|c|}
\hline Strategy & Sefinition & Example \\
\hline \multirow[t]{6}{*}{$\begin{array}{l}\text { Organizing } \\
\text { understandings }\end{array}$} & $\begin{array}{l}\text { Simplify the situation by combining } \\
\text { information based on what is relevant } \\
\text { or important to the situation }\end{array}$ & $\begin{array}{l}\text {...just putting everything together a lot of different } \\
\text { pieces }\end{array}$ \\
\hline & By controlling amount & $\begin{array}{l}\text { Simplicity, I look at my options, at what the assets I } \\
\text { have available. Unspecified number of Chinooks, } 2 \\
\text { HMMWVs and TOWs, when I look at that I think, well } \\
\text { that's going to increase my mass, which l'd [like]in this } \\
\text { case. However, it starts to push me out of the } \\
\text { simplicity area, it starts to complicate my economy of } \\
\text { force. }\end{array}$ \\
\hline & By comparing & $\begin{array}{l}\text { I don't know what l'd want to do with these outer } \\
\text { bldgs, especially if there's } 60 \text { guys roaming around. } \\
\text { Because if people operated like we normally operate, } \\
\text { maybe one of these is like a bunkhouse where there } \\
\text { are } 40 \text { guys in the bunkhouse and } 20 \text { guys out on } \\
\text { guard shift. So that becomes almost a key target. }\end{array}$ \\
\hline & By typecasting & $\begin{array}{l}\text { An assault force for } A \text { that will actually enter the bldg } \\
\text { and an assault force for B that will actually enter that } \\
\text { bldg and then security force for NE, security force for } \\
\text { SW ... and I'm basically using a breaching } \\
\text { methodology because we don't do these ... which is } \\
\text { to isolate the objective so isolate it and then secure it } \\
\text { and then for breaching it would be ... What I'm doing } \\
\text { is that I'm taking a model that I'm familiar with which is } \\
\text { breaching, and trying to build it into a raid. }\end{array}$ \\
\hline & By saving resources & $\begin{array}{l}\text { The artillery's mission is to take out all the bad guys. } \\
\text { We don't have enough assets to take them all out, so } \\
\text { we've got to focus our efforts on what we rehearsed } \\
\text { and what we planned on and we probably get about } 5 \\
\text { missions. If we do } 5 \text { real good missions in the battle, } \\
\text { then chances are that we'll be real successful in } \\
\text { meeting the brigade commander's intent }\end{array}$ \\
\hline & By avoiding uncertainty & $\begin{array}{l}\text { How long will it take me to get around. Do I know that } \\
\text { I can even get around there because this guy been } \\
\text { over here yet. The scouts have been down here and } \\
\text { know this route. I know who's there. I don't know } \\
\text { what's over here so I'm... for lack of anything better, } \\
\text { l'm going to take the information I know that I can } \\
\text { confirm and go with that. }\end{array}$ \\
\hline $\begin{array}{l}\text { Comparison } \\
\text { testing }\end{array}$ & $\begin{array}{l}\text { Considering some dimension of the } \\
\text { situation in different ways to evaluate } \\
\text { the implications of each on the } \\
\text { situation }\end{array}$ & $\begin{array}{l}\text { Well, right away because, well I guess you could. The } \\
\text { first decision, I guess, is do you want to try and do } \\
\text { this, well I guess you can assume that you'll be able to } \\
\text { do it stealthily. You'd want to see if you could just do } \\
\text { it quietly and not even have to deal with this } 15 \text { minute } \\
\text { reaction force. But you're probably not going to be } \\
\text { able to do that, given what's bringing you in. That will } \\
\text { tip them right away. So right away, I would bring in } \\
\text { the tows to cover, I think one of the avenues of } \\
\text { approach and rely on the AH64s to cover the other } \\
\text { one, because you're going to want to be able to take } \\
\text { out that reinforcement right away. Then the next } \\
\text { decision is exactly how you're going to task organize } \\
\text { to cover both building Alpha and Bravo. }\end{array}$ \\
\hline
\end{tabular}


Natural Strategies, Definitions, and Examples (continued)

\begin{tabular}{|c|c|c|}
\hline Strategy & Deffitition & Exarnole \\
\hline \multirow[t]{4}{*}{$\begin{array}{l}\text { Information } \\
\text { credibility }\end{array}$} & \multicolumn{2}{|l|}{$\begin{array}{l}\text { Consider the source of the information } \\
\text { when assessing the quality of the } \\
\text { information }\end{array}$} \\
\hline & Of the medium & $\begin{array}{l}\text { if they can draw it, you know, this is what they looked } \\
\text { like when they came across, and they show me a } \\
\text { picture, I obviously know from that person that they've } \\
\text { done something other than just seeing it. }\end{array}$ \\
\hline & Of the person & $\begin{array}{l}\text { Eyes on target is the best intel we can get and if I } \\
\text { have my own soldiers out there that I trust and I } \\
\text { understand that they understand that an OP4 vehicle } \\
\text { from a friendly vehicle and they're giving me back the } \\
\text { information, that's what I would go with. }\end{array}$ \\
\hline & Of the role & $\begin{array}{l}\text { My two information sources were LRSDs among the } \\
\text { scouts. That's about as reliable as it gets, and as } \\
\text { accurate as it gets. So that affected my decision. } \\
\text { And I could use them as facts, not as assumptions, } \\
\text { because it was reliable and accurate. }\end{array}$ \\
\hline $\begin{array}{l}\text { Monitoring } \\
\text { knowledge }\end{array}$ & $\begin{array}{l}\text { Assessing the state or quality of } \\
\text { understandings about the information } \\
\text { being used. }\end{array}$ & $\begin{array}{l}\text { Whenever we moved we factored in a good amount of } \\
\text { time to allow for us to get a little disoriented, as I call } \\
\text { it. }\end{array}$ \\
\hline Rule use & $\begin{array}{l}\text { Simplify the situation and solution by } \\
\text { relying on automatic behaviors or } \\
\text { standard operating procedures }\end{array}$ & $\begin{array}{l}\text { Back to the standard training with many, many years, } \\
\text { you fix an enemy force, you bypass an enemy force, } \\
\text { and get to a key position of terrain, and then destroy } \\
\text { the force at our leisure. We really only developed one } \\
\text { solution. }\end{array}$ \\
\hline $\begin{array}{l}\text { Predict a future } \\
\text { state }\end{array}$ & $\begin{array}{l}\text { Characterize a particular point in time } \\
\text { so that its implications can be } \\
\text { evaluated, used in mental simulations, } \\
\text { etc. }\end{array}$ & $\begin{array}{l}\text { I told him if you don't want to be here you don't have } \\
\text { to be here I said I can get you out of here. I can get } \\
\text { you out in fifteen minutes so all I got to do is call the } \\
\text { commander call someone over here and you no } \\
\text { longer will be a tank commander. I guess I proposed } \\
\text { a possible solution to him whether he wanted to } \\
\text { continue doing his job and keep it or not. }\end{array}$ \\
\hline Goal comparison & $\begin{array}{l}\text { Resolving conflicts between goals by } \\
\text { evaluating the attributes and } \\
\text { implications of each goal. }\end{array}$ & $\begin{array}{l}\text { Wasn't able to keep my platoon alive, but I believe we } \\
\text { basically accomplished the mission, because we were } \\
\text { able to destroy three times what we were supposed to } \\
\text { be able to destroy. }\end{array}$ \\
\hline Goal negotiation & $\begin{array}{l}\text { Consider the attributes and } \\
\text { implications of goals to accomplish all, } \\
\text { resolve incompatibility, or balance } \\
\text { outcomes. }\end{array}$ & $\begin{array}{l}\text { My desire is to save as many soldiers without } \\
\text { endangering the lives of my soldiers there is a fine } \\
\text { line between these two.,... we have to be as close as } \\
\text { possible and that puts us in extreme danger. So we } \\
\text { have a balance between those two.... }\end{array}$ \\
\hline Goal questioning & $\begin{array}{l}\text { Ask whether the held goal is still } \\
\text { appropriate given a change in the } \\
\text { situation. }\end{array}$ & $\begin{array}{l}\text { I don't think that the answer in this situation is to } \\
\text { charge in and knock him out of the way. We probably } \\
\text { have the forces to take the assembly area, but the } \\
\text { question would be why. }\end{array}$ \\
\hline Goal prioritization & $\begin{array}{l}\text { Order goals in term of their importance } \\
\text { to the situation. }\end{array}$ & $\begin{array}{l}\text { What we were going to do. If we were going to stay } \\
\text { tight, if we were going to continue to push on, and } \\
\text { doing a risk assessment of whether the training } \\
\text { actually worth the jeopardy that a lot of the soldiers } \\
\text { were in. }\end{array}$ \\
\hline Goal choice & $\begin{array}{l}\text { Select a goal for current action from } \\
\text { among identified goals. }\end{array}$ & $\begin{array}{l}\text { Do I secure favorable terrain and then from that point } \\
\text { set some near objectives and some engagement } \\
\text { areas to defend against the enemy or do I continue to } \\
\text { drive through and maybe try to gain the river line by } \\
\text { wiping these guys out and try to posture myself along } \\
\text { the river line for additional forces moving south? }\end{array}$ \\
\hline $\begin{array}{l}\text { Considering } \\
\text { others' goals }\end{array}$ & $\begin{array}{l}\text { Considering the motivation and intent } \\
\text { of others in the situation (enemy, } \\
\text { commander, etc.) }\end{array}$ & $\begin{array}{l}\text { Is he trying to set up a defense or is he trying to roll } \\
\text { over me? }\end{array}$ \\
\hline
\end{tabular}


Natural Strategies, Definitions, and Examples (continued)

\begin{tabular}{|c|c|c|}
\hline Strategy & Definition & Exanole \\
\hline $\begin{array}{l}\text { Use situation } \\
\text { constraints to } \\
\text { determine } \\
\text { priorities }\end{array}$ & $\begin{array}{l}\text { Shape the attributes of the solution } \\
\text { around the limitations of the situation. }\end{array}$ & $\begin{array}{l}\text { Can't go in from the west at all. So that's another } \\
\text { limitation that you have. So what I would do is, I } \\
\text { would prioritize things that I think are most important, } \\
\text { because we're not going to be able to totally prepare } \\
\text { for this if we don't have as much time. }\end{array}$ \\
\hline $\begin{array}{l}\text { Anchoring on } \\
\text { information from } \\
\text { authority }\end{array}$ & $\begin{array}{l}\text { Staying with the last concrete } \\
\text { information or mission in the face of } \\
\text { new uncertainty }\end{array}$ & $\begin{array}{l}\text { If I could not get hold of anybody, my last instructions } \\
\text { were to occupy this assembly area, so instead of } \\
\text { occupying nice and quiet it would be a... basically be } \\
\text { a hasty attack onto the assembly area. }\end{array}$ \\
\hline $\begin{array}{l}\text { Compensating for } \\
\text { missing } \\
\text { information }\end{array}$ & $\begin{array}{l}\text { Handle uncertainty by making up for } \\
\text { missing information using other } \\
\text { means, e.g., flexibility or giving more } \\
\text { weight to what is known (using more } \\
\text { force, etc) }\end{array}$ & $\begin{array}{l}\text { So my task organization would then have to be more } \\
\text { flexible if I could not get that information. }\end{array}$ \\
\hline $\begin{array}{l}\text { Grouping } \\
\text { information } \\
\text { (clustering) }\end{array}$ & $\begin{array}{l}\text { Creating subgroups of information } \\
\text { based on a superordinate } \\
\text { characteristic which is related to and } \\
\text { facilitates reaching the goal }\end{array}$ & $\begin{array}{l}\text { Looking at the equipment that we had on hand and } \\
\text { now I am talking about the way the vehicles were, } \\
\text { base line what they looked like to begin with. Did I } \\
\text { have the, in HMV number one, do I have the space to } \\
\text { put two radios in? If it is in the no column then I know } \\
\text { that I am going to need to allocate two man hours for } \\
\text { that. If it is in the yes column I know that it is going to } \\
\text { be about an hour and a half, uh two hours and a half. }\end{array}$ \\
\hline $\begin{array}{l}\text { Infer new } \\
\text { information based } \\
\text { on missing } \\
\text { information }\end{array}$ & $\begin{array}{l}\text { Making assumptions about a situation } \\
\text { based on information which is not } \\
\text { present but that ordinarily would be } \\
\text { expected to be present }\end{array}$ & $\begin{array}{l}\text { But I'd expect, since there aren't any vehicles } \\
\text { reported there, I'm sure there's probably one or two } \\
\text { vehicles hiding there undetected. Military vehicles. }\end{array}$ \\
\hline Reinterpretation & $\begin{array}{l}\text { Taking a new perspective on the } \\
\text { problem or changing one's } \\
\text { understanding of the situation }\end{array}$ & $\begin{array}{l}\text { And the reason why I say that is, if the big picture is } \\
\text { I'm supposed to be getting ready to be the lead effort } \\
\text { of the main attack across the river line; so there's that } \\
\text { big picture. But the big picture now rapidly changes } \\
\text { because the farthest thing from my mind right now, } \\
\text { which is not necessarily right is that mission now. } \\
\text { Now I see my big picture as being one of clarifying a } \\
\text { very unknown situation. So the big picture has } \\
\text { changed, I guess, in my mind. It went from the one to } \\
\text { the other. }\end{array}$ \\
\hline $\begin{array}{l}\text { Considering } \\
\text { situational error }\end{array}$ & $\begin{array}{l}\text { Recognizing that variability exists in } \\
\text { the environment and its implications }\end{array}$ & $\begin{array}{l}\text { I started relying more on my map and compass, } \\
\text { slowing down not getting to anxious or too nervous. } \\
\text { Whenever we moved we factored in a good amount of } \\
\text { time to allow for us to get a little disoriented as I call it. }\end{array}$ \\
\hline $\begin{array}{l}\text { Considering } \\
\text { situational error }\end{array}$ & $\begin{array}{l}\text { Recognizing that variability exists in } \\
\text { the environment and its implications }\end{array}$ & $\begin{array}{l}\text { I started relying more on my map and compass, } \\
\text { slowing down not getting to anxious or too nervous. } \\
\text { Whenever we moved we factored in a good amount of } \\
\text { time to allow for us to get a little disoriented as I call it. }\end{array}$ \\
\hline $\begin{array}{l}\text { Feedback- } \\
\text { seeking actions }\end{array}$ & $\begin{array}{l}\text { Initiating a behavior to gauge the } \\
\text { results and to use this as information } \\
\text { for future behavior. }\end{array}$ & $\begin{array}{l}\text { Attack by fire somewhere here, then I got to read that. } \\
\text { Got two roads that go around my assembly area. } \\
\text { That gives me opportunity to flex my tank team, either } \\
\text { right...or left, depending on how this mech team sets } \\
\text { up the situation. }\end{array}$ \\
\hline $\begin{array}{l}\text { Abstract trade- } \\
\text { offs }\end{array}$ & $\begin{array}{l}\text { Making qualitative comparisons } \\
\text { between beliefs, goals, options, etc. }\end{array}$ & $\begin{array}{l}\text { I'm not worried about using resources, expending } \\
\text { resources when they're material things, but when we } \\
\text { start talking about resources being human lives, I'm } \\
\text { real uneasy about that. So you're going to have to do } \\
\text { your very best to balance time and information, } \\
\text { because if you wait too long to make a decision, you } \\
\text { might end up losing more lives as well. }\end{array}$ \\
\hline Estimation & $\begin{array}{l}\text { Using an attribute of the situation (such } \\
\text { as size) to assign resources }\end{array}$ & $\begin{array}{l}\text { My task organization is I have to break them down } \\
\text { into } A \text { and } B \text {, and } A \text { looks a little bigger than } B \text {. I got } \\
\text { maybe about } 60 \text { people, and looking at the buildings, } \\
\text { maybe I got a } 40 / 20 \text { ratio, something like that, } \\
\text { because this building looks almost twice the size of } \\
\text { that building. }\end{array}$ \\
\hline
\end{tabular}

